\title{
Photodynamic therapy for neovascular age-related macular degeneration (Review)
}

Wormald R, Evans J, Smeeth L, Henshaw K

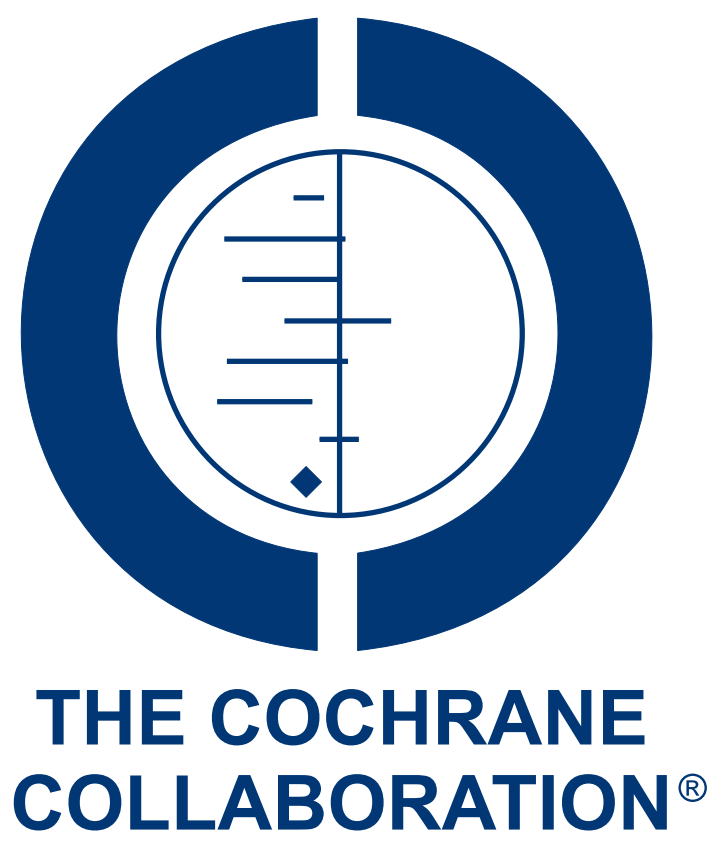

This is a reprint of a Cochrane review, prepared and maintained by The Cochrane Collaboration and published in The Cochrane Library 2005, Issue 4

http://www.thecochranelibrary.com

\section{WILEY}

Photodynamic therapy for neovascular age-related macular degeneration (Review)

Copyright @ 2007 The Cochrane Collaboration. Published by John Wiley \& Sons, Ltd. 
TABLE OF CONTENTS

ABSTRACT . . . . . . . . . . . . . . . . . . . . . . . . . . . . . . . . . . . . . . . . . . . . . . . . 1

PLAIN LANGUAGE SUMMARY . . . . . . . . . . . . . . . . . . . . . . . . . . . . . . . . . . . .

BACKGROUND . . . . . . . . . . . . . . . . . . . . . . . . . . . . . . . . . . . . . 2

OBJECTIVES . . . . . . . . . . . . . . . . . . . . . . . . . . . . . . . . . . . . . . 2

CRITERIA FOR CONSIDERING STUDIES FOR THIS REVIEW . . . . . . . . . . . . . . . . . . . . . 2

SEARCH METHODS FOR IDENTIFICATION OF STUDIES . . . . . . . . . . . . . . . . . . . . . . . . . $\quad$. 3

METHODS OF THE REVIEW . . . . . . . . . . . . . . . . . . . . . . . . . . . . . . . . . . . c 4

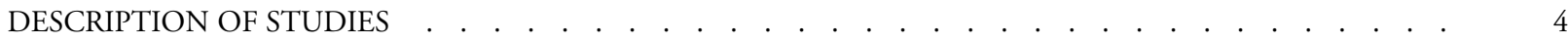

METHODOLOGICAL QUALITY . . . . . . . . . . . . . . . . . . . . . . . . . . . . . . . . . . 5

RESULTS . . . . . . . . . . . . . . . . . . . . . . . . . . . . . . . . 5

DISCUSSION . . . . . . . . . . . . . . . . . . . . . . . . . . . . . . . . . . . . . . . . . . .

AUTHORS' CONCLUSIONS . . . . . . . . . . . . . . . . . . . . . . . . . . . . . . . . . . . . . . . . . $\quad .9$

POTENTIAL CONFLICT OF INTEREST . . . . . . . . . . . . . . . . . . . . . . . . . . . . . . . . . . . 10

ACKNOWLEDGEMENTS . . . . . . . . . . . . . . . . . . . . . . . . . . . . . . . . . . . . . . . . . 10

SOURCES OF SUPPORT . . . . . . . . . . . . . . . . . . . . . . . . . . . . . . . . . . . . . . . . .

REFERENCES . . . . . . . . . . . . . . . . . . . . . . . . . . . . . . . . . . . . . . 10

TABLES . . . . . . . . . . . . . . . . . . . . . . . . . . . . . . . . . . . . . . . 12

Characteristics of included studies . . . . . . . . . . . . . . . . . . . . . . . . . . . . . . . . . .

Characteristics of excluded studies . . . . . . . . . . . . . . . . . . . . . . . . . . . . . . . . . . .

Characteristics of ongoing studies . . . . . . . . . . . . . . . . . . . . . . . . . . . . . . . . . . . .

ANALYSES . . . . . . . . . . . . . . . . . . . . . . . . . . . . . . . . . . . . . . . . . . . . . . . . . . 14

Comparison 01. PHOTODYNAMIC THERAPY WITH VERTEPORFIN VERSUS PLACEBO ．．．． . . 14

INDEX TERMS . . . . . . . . . . . . . . . . . . . . . . . . . . . . . . . . . . . . . . . . 15

COVER SHEET . . . . . . . . . . . . . . . . . . . . . . . . . . . . . . . . . . . . . . . . . . .

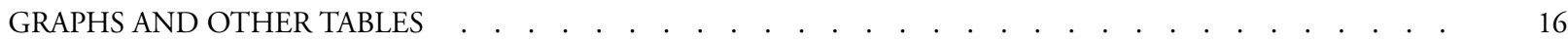

Analysis 01.01. Comparison 01 PHOTODYNAMIC THERAPY WITH VERTEPORFIN VERSUS PLACEBO, 16

Outcome 01 Overall effect: $>=3$ lines lost at 12 months

Analysis 01.02. Comparison 01 PHOTODYNAMIC THERAPY WITH VERTEPORFIN VERSUS PLACEBO, 17

Outcome 02 Overall effect: $>=3$ lines lost at 24 months _ . . . . . . . . . . . . . . . . . . . . .

Analysis 01.03. Comparison 01 PHOTODYNAMIC THERAPY WITH VERTEPORFIN VERSUS PLACEBO,

Outcome 03 Overall effect: $>=6$ lines lost at 12 months . . . . . . . . . . . . . . . . . . . . . . . . .

Analysis 01.04. Comparison 01 PHOTODYNAMIC THERAPY WITH VERTEPORFIN VERSUS PLACEBO,

Outcome 04 Overall effect: $>=6$ lines lost at 24 months

Analysis 01.05. Comparison 01 PHOTODYNAMIC THERAPY WITH VERTEPORFIN VERSUS PLACEBO,

Outcome 05 Classic CNV subgroups: >=3 lines lost at 12 months

Analysis 01.06. Comparison 01 PHOTODYNAMIC THERAPY WITH VERTEPORFIN VERSUS PLACEBO,

Outcome 06 Classic CNV subgroups: $>=3$ lines lost at 24 months . . . . . . . . . . . . . . . . . . . . . . . .

Analysis 01.07. Comparison 01 PHOTODYNAMIC THERAPY WITH VERTEPORFIN VERSUS PLACEBO,

Outcome 07 Overall effect: contrast sensitivity: $>=6$ letters lost at 24 months . . . . . . . . . . . . . . . .

Analysis 01.08. Comparison 01 PHOTODYNAMIC THERAPY WITH VERTEPORFIN VERSUS PLACEBO,

Outcome 08 Overall effect: contrast sensitivity: >= 15 letters lost at 24 months

Analysis 01.09. Comparison 01 PHOTODYNAMIC THERAPY WITH VERTEPORFIN VERSUS PLACEBO,

Outcome 09 Adverse effects: acute severe visual acuity decrease . . . . . . . . . . . . . . . . . . . . . . . . . . .

Analysis 01.10. Comparison 01 PHOTODYNAMIC THERAPY WITH VERTEPORFIN VERSUS PLACEBO,

Outcome 10 Adverse effects: visual disturbance

Analysis 01.11. Comparison 01 PHOTODYNAMIC THERAPY WITH VERTEPORFIN VERSUS PLACEBO,

Outcome 11 Adverse effects: injection site

Analysis 01.12. Comparison 01 PHOTODYNAMIC THERAPY WITH VERTEPORFIN VERSUS PLACEBO,

Outcome 12 Adverse effects: infusion-related back pain

Analysis 01.13. Comparison 01 PHOTODYNAMIC THERAPY WITH VERTEPORFIN VERSUS PLACEBO,

Outcome 13 Adverse effects: allergic reactions . . . . . . . . . . . . . . . . . . . . . . . . . . . .

Photodynamic therapy for neovascular age-related macular degeneration (Review)

Copyright @ 2007 The Cochrane Collaboration. Published by John Wiley \& Sons, Ltd 
Analysis 01.14. Comparison 01 PHOTODYNAMIC THERAPY WITH VERTEPORFIN VERSUS PLACEBO,

Outcome 14 Adverse effects: photosensitivity reactions 


\title{
Photodynamic therapy for neovascular age-related macular degeneration (Review)
}

\author{
Wormald R, Evans J, Smeeth L, Henshaw K
}

This record should be cited as:

Wormald R, Evans J, Smeeth L, Henshaw K. Photodynamic therapy for neovascular age-related macular degeneration. Cochrane

Database of Systematic Reviews 2005, Issue 4. Art. No.: CD002030. DOI: 10.1002/14651858.CD002030.pub2.

This version first published online: 19 October 2005 in Issue 4, 2005.

Date of most recent substantive amendment: 23 August 2005

\begin{abstract}
A B S T R A C T
Background

In neovascular age-related macular degeneration (AMD) new vessels grow under the retina distorting vision and leading to scarring. This is exacerbated if the blood vessels leak. Photodynamic therapy (PDT) has been investigated as a way to treat the neovascular membranes without affecting the retina.
\end{abstract}

\section{Objectives}

The aim of this review was to examine the effects of PDT in the treatment of neovascular AMD.

\section{Search strategy}

We searched the Cochrane Central Register of Controlled Trials (CENTRAL) (which includes the Cochrane Eyes and Vision Group Trials Register) on The Cochrane Library (Issue 1, 2005), MEDLINE (1966 to January 2005), EMBASE (1980 to January 2005). We used the Science Citation Index to search for reports that cited relevant studies. We contacted experts in the field and searched the reference lists of relevant studies.

\section{Selection criteria}

We included randomised trials of PDT in people with choroidal neovascularisation due to AMD.

\section{Data collection and analysis}

Two authors independently extracted the data. Relative risks were combined using a fixed-effect model after testing for heterogeneity.

\section{Main results}

Two published trials were identified that randomised 948 participants to verteporfin therapy compared to 5\% dextrose in water. Both trials were performed by the same investigators using largely the same clinical centres and funded by manufacturers of verteporfin. Outcome data were available at 12 and 24 months after the first treatment. Participants received on average five treatments over two years. The relative risk of losing three or more lines of visual acuity at 24 months comparing the intervention with the control group was 0.77 (95\% confidence interval 0.69 to 0.87 ). The relative risk of losing six or more lines of visual acuity at 24 months comparing the intervention with the control group was 0.62 ( $95 \%$ confidence interval 0.50 to 0.76 ). The results at 12 months were similar to those at 24 months. The most serious adverse outcome, acute (within 7 days of treatment) severe visual acuity decrease, occurs in about one in 50 patients.

\section{Authors' conclusions}

Photodynamic therapy in people with choroidal neovascularisation due to AMD is probably effective in preventing visual loss though there is doubt about the size of the effect. Outcomes and potential adverse effects of this treatment should be monitored closely. Further independent trials of verteporfin are required to establish that the effects seen in this study are consistent and to examine important issues not yet addressed, particularly relating to quality of life and cost. 


\section{PLAIN LANGUAGE SUMMARY}

Photodynamic therapy may reduce vision loss caused by one type of age-related macular degeneration but more research is needed

Age-related macular degeneration (AMD) affects the macula, the centre of the retina (the light-sensitive area inside the eye). One type is called 'wet' or neovascular AMD, as new blood vessels develop in the macula. These can leak and scar the eye causing vision loss. Photodynamic therapy involves injecting chemicals into the blood stream then radiating light as the chemicals flow through these new blood vessels in the eye. This aims to activate the chemicals enough to destroy the vessels but not enough to hurt the eye. The review found evidence that this may reduce vision loss caused by neovascular AMD but more research is needed.

\section{B A C K G R O U N D}

Age-related macular degeneration (AMD) is a disease affecting the macula, the central area of the retina. The disease is defined as degeneration of the macula in older people (aged over 50) with no other apparent cause for the degeneration.

There are several signs in the retina that are associated with increasing age and increased risk of developing age-related macular degeneration. These signs, known as age-related maculopathy, include the presence of drusen (yellow spots beneath the retina) and pigmentary disturbance. In general age-related maculopathy is not associated with visual loss. Some people with age-related maculopathy will go on to develop age-related macular degeneration.

There are two main types of AMD. In geographic atrophy (dry) AMD, the retinal pigment epithelium is lost completely in localised areas. In neovascular (wet) AMD, sub-retinal neovascular membranes (new blood vessels) develop beneath the retina. These are associated with scarring of the retina that affects vision. The new vessels can leak causing haemorrhage that leads to larger scars or macular oedema and significant loss of vision. This review was concerned with treatment for neovascular age-related macular degeneration.

Sub-retinal neovascular membranes are defined as classic or occult according to their appearance on fluorescein angiography, in which fluorescent dye is injected intravenously and photographed as it passes through the blood vessels of the eye. Classic membranes are clearly delineated and leak fluorescein uniformly. Occult membranes are often hidden or their extent is hard to delineate, and fluorescein leakage is patchy. It is thought that these two angiographic patterns reflect the different extent to which the vessels have penetrated the retinal pigment epithelium, occult vessels lying underneath the retinal pigment epithelium. Some lesions may have both classic and occult components.

Trials have shown that early laser photocoagulation of classic extrafoveal membranes (those not directly underneath the fovea at the centre of the macula) could delay the loss of vision in a small number of patients (MPS 1994). However, most patients present with subfoveal membranes, and whilst photocoagulation can limit the extent of the subsequent visual loss, it causes immediate loss of central vision due to the concurrent destruction of the overlying retina.

Photodynamic therapy, originally used in the treatment of cancer, has been investigated as a way to treat the neovascular membranes without affecting the retina. Photoreactive chemicals are injected into the patient and irradiated with light as they pass through the neovascular membranes. This light is strong enough to activate the chemicals, causing them to emit free radicals that destroy the blood vessels, but is not strong enough to cause damage to the overlying retina.

\section{O B J E C T I V E S}

The aim of this review was to examine the effects of photodynamic therapy in the treatment of neovascular age-related macular degeneration.

\section{CRITERIA FOR CONSIDERING STUDIES FOR THIS REVIEW}

\section{Types of studies}

We included randomised controlled trials.

\section{Types of participants}

We included trials in which participants were people with neovascular age-related macular degeneration as defined by the study investigators.

\section{Types of intervention}

We included any study in which photodynamic therapy was compared to another treatment, placebo or no treatment.

\section{Types of outcome measures}

The primary outcome for this review was prevention of visual loss. Any well-defined outcome based on visual acuity was used depending on the way in which authors presented trial data. Other validated measures of visual loss, such as contrast sensitivity, were used where available.

The secondary outcomes for this review were: 
- new vessel growth;

- quality of life measures - any validated measurement scale which aims to measure the impact of visual function loss on quality of life of participants;

- any adverse outcomes as reported in trials.

\section{SEARCH METHODSFOR IDENTIFICATIONOF TUDIES}

See: methods used in reviews.

\section{Electronic searches}

We searched the Cochrane Central Register of Controlled Trials (CENTRAL) (which contains the Cochrane Eyes and Vision Group Trials Register) on The Cochrane Library, MEDLINE and EMBASE.

We used the following strategy to search CENTRAL Issue 1, 2005:

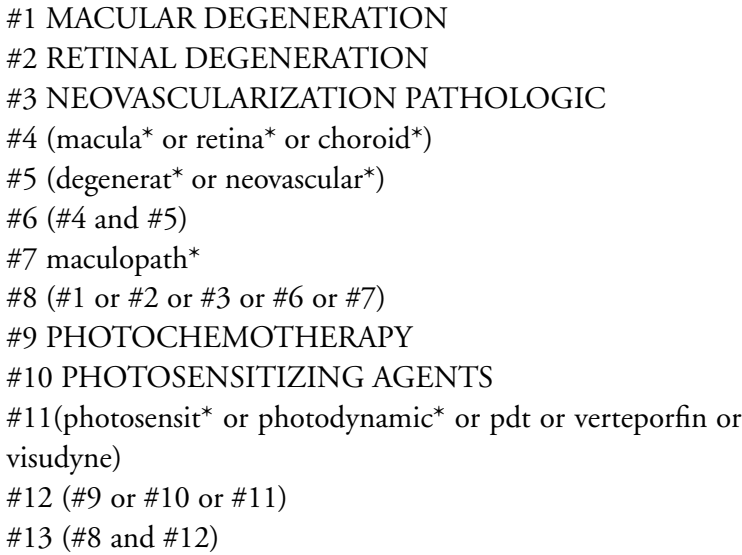

We used the following strategy combined with the Cochrane highly sensitive search strategy (Higgins 2005a) to search MEDLINE on SilverPlatter to January 2005.

\#1 explode "Macular-Degeneration" / all SUBHEADINGS in MIME,MJME

\#2 explode "Retinal-Degeneration" / all SUBHEADINGS in MIME,MJME

\#3 explode "Choroidal-Neovascularization" / all SUBHEADINGS in MIME,MJME

\#4 ( ((macul* or retina* or choroid*)near (degener* or neovasc $\left.\left.{ }^{*}\right)\right)$ in TI )or( ((macul* or retina* or choroid*) near (degener* or neovasc $\left.c^{*}\right)$ in $\mathrm{AB}$ )

\#5 maculopath* in TI

\#6 maculopath* in $\mathrm{AB}$

$\# 7 \# 1$ or \#2 or \#3 or \#4 or \#5 or \#6

\#8 explode "Photochemotherapy-" / all SUBHEADINGS in MIME,MJME
\#9 explode "Photosensitizing-Agents" / all SUBHEADINGS in MIME,MJME

\#10 ( ((photosenstiti* near agent*)or porphyrin* or benzoporphyrin*) in AB )or( ((photosenstiti* near agent*)or porphyrin* or benzoporphyrin*) in NM )or( ((photosenstiti* near agent*)or porphyrin* or benzoporphyrin*) in TI ) \#11 ( (photodynamic* or PDT) in AB )or( (photodynamic* or PDT) in TI )

\#12 ( (verteporfin or visudyne) in AB )or( (verteporfin or visudyne) in TI )

$\# 13 \# 8$ or \#9 or \#10 or \#11 or \#12

$\# 14 \# 7$ and \#13

We used the following strategy to search EMBASE on Ovid to January 2005.

1. exp Retina Macula Age Related Degeneration/

2. exp Retina Degeneration/

3. exp "Neovascularization (Pathology)"/

4. exp Subretinal Neovascularization/

5. ( (macul\$ or retina $\$$ or choroid $\$)$ adj5 (degener $\$$ or neovasc\$)).ab,ti.

6. maculopath\$.ab,ti.

7. 1 or 2 or 3 or 4 or 5 or 6

8. exp Photodynamic Therapy/

9. exp Photosensitizing Agent/

10. (photodynamic\$ or PDT).ab,ti.

11. (photosensit\$ adj3 agent\$).ab,ti.

12. (verteporfin or visudyne).ab,tn,ti.

13. 8 or 9 or 10 or 11 or 12

14. 7 and 13

To identify randomised controlled trials we combined this search with the following strategy.

\#1 Randomized Controlled Trial/

\#2 exp Randomization/

\#3 Double Blind Procedure/

\#4 Single Blind Procedure/

\#5 random $\$$.ab,ti.

$\# 6 \# 1$ or \#2 or \#3 or \#4 or \#5

\#7 (animal or animal experiment).sh.

\#8 human.sh.

\#9 \#7 and \#8

\#10 \#7 not \#9

\#11 \#6 not \#10

\#12 Clinical Trial/

\#13 (clin\$ adj3 trial\$).ab,ti.

$\# 14$ ((singl\$ or doubl\$ or trebl\$ or tripl\$) adj3 (blind $\$$ or mask\$)).ab,ti.

\#15 exp PLACEBO/

\#16 placebo\$.ab,ti.

\#17 random\$.ab,ti.

\#18 experimental design/

\#19 Crossover Procedure/

Photodynamic therapy for neovascular age-related macular degeneration (Review)

Copyright @ 2007 The Cochrane Collaboration. Published by John Wiley \& Sons, Ltd 
\#20 exp Control Group/

\#21 exp LATIN SQUARE DESIGN/

$\# 22 \# 12$ or $\# 13$ or $\# 14$ or $\# 15$ or \#16 or \#17 or \#18 or \#19 or

$\# 20$ or \#21

\#23 \#22 not \#10

\#24 \#23 not \#11

\#25 exp Comparative Study/

\#26 exp Evaluation/

\#27 exp Prospective Study/

\#28 (control\$ or prospectiv\$ or volunteer\$).ab,ti.

$\# 29 \# 25$ or \#26 or \#27 or \#28

\#30 \#29 not \#10

\#31 \#30 not (\#11 or \#23)

$\# 32 \# 11$ or \#24 or \#31

\section{Manual searches}

We used the Science Citation Index to search for reports that cited relevant study reports. We contacted experts in the field for information about further trials and we searched the reference lists of relevant studies for further trial reports.

\section{METHODSOF THE REVIEW}

\section{Selection of trials}

Two authors independently scanned the titles and abstracts resulting from the electronic searches. We obtained full copies of all potentially or definitely relevant articles. Two review authors assessed the full copies according to the 'Criteria for considering studies for this review'. Only articles meeting these criteria were assessed for quality.

\section{Assessment of methodological quality}

Two authors independently assessed study quality according to methods set out in Section 6 of the Cochrane Handbook for Systematic Reviews of Interventions (Higgins 2005b). The authors were not masked to any trial details during the assessment. Four parameters of quality were considered: allocation concealment and method of allocation to treatment, masking of providers and recipients of care, masking of outcome assessment, and completeness of follow up. Each parameter of trial quality was graded: A (adequate); B (unclear); C (inadequate). Disagreement between the review authors on assessments was resolved by discussion. We contacted the trial authors for clarification on any parameter graded $\mathrm{B}$ and we excluded any trial scoring $\mathrm{C}$ on allocation concealment.

\section{Data collection}

Two authors independently extracted data using a form developed by the Cochrane Eyes and Vision Group (available from the editorial base). We resolved discrepancies by discussion. Two review authors independently entered data into RevMan 4.2 and we checked any inconsistencies between the two against the study report.

\section{Data synthesis}

Our original data analysis plan was to summarise data from studies collecting similar outcome measures with similar follow-up times using the Peto method, after testing for heterogeneity between trial results using a standard chi squared test. The main outcome analysed, loss of three or more lines of visual acuity at 12 and 24 months follow up, occurred relatively frequently in the trial cohort. The odds ratio, therefore, does not approximate to the relative risk. We present relative risks in this review. We planned to conduct sensitivity analyses to determine the effect of excluding studies given a grade of $\mathrm{C}$ (inadequate) on any parameter of quality but to date this has not been necessary.

\section{DESCRIPTIONOF STUDIES}

\section{Finding the trials}

The original electronic searches identified 76 reports. We found one randomised controlled trial (TAP 1999). Since the searches were updated in February 2001, May 2002 and January 2003 one further study was identified and included in the review (VIP 2001).

A further search update was conducted in January 2005. A total of 284 new reports were found. No reports of new trials were found though there were a number of new reports from existing trials including new outcomes on contrast sensitivity (Rubin 2002), central visual field function (Schmidt-Erfurth 2004) and subretinal neovascular morphology (Schmidt-Erfurth 2003). In addition we found one systematic review (Meads 2004), a metaanalysis of safety results in TAP and VIP (Azab 2004) and a costutility analysis (Hopley 2004). A report on severe visual acuity decrease in TAP and VIP (Arnold 2004) was also considered relevant. An outcome study reporting visual function and related quality of life was found (Armbrecht 2004). A number of papers from the TAP and VIP studies were found including guidelines for evaluation of fluorescein angiographic findings and treatment (Barbazetto 2003), determinants of outcome according to lesion size, visual acuity and lesion composition (Blinder 2003), baseline lesion composition's impact on vision outcome (Bressler 2002) and natural history of minimally classic lesions (Bressler 2004).

We found no reports from the studies identified in the 'Characteristics of ongoing trials' table but one traditional review of PDT (Woodburn 2002) mentions trials on other agents, such as etiopurpurin (Purlytin) and motexafin lutetium (Optrin) undergoing phase III and phase II trials respectively.

\section{Summary of the characteristics of included studies}

Below is a summary of the included studies. Details can be found in the 'Characteristics of included studies' table.

TAP 1999 was a multicentre study investigating the safety and effectiveness of verteporfin (Visudyne; CIBA Vision Corp, USA). It was conducted in 22 ophthalmology practices in Europe and

Photodynamic therapy for neovascular age-related macular degeneration (Review)

Copyright (c) 2007 The Cochrane Collaboration. Published by John Wiley \& Sons, Ltd 
North America. Participants were people with subfoveal choroidal neovascularisation (CNV) caused by age-related macular degeneration. The majority of participants were white $(98 \%)$ with a mean age of 75 years. TAP 1999 was originally devised as two concurrent trials in order to comply with regulatory agency requirements. The study protocols were identical. Ten of the clinical centres were assigned to study A and 12 to study B. As the results of the trials were similar and the investigators analysed and presented the data as one trial we have also assessed it as one trial.

The VIP 2001 study was very similar to the TAP 1999 study. It was conducted in 28 practices, most of whom had also participated in TAP 1999. As for TAP 1999, the majority of participants were white $(98 \%)$ with a mean age of 75 years.

In both trials verteporfin $\left(6 \mathrm{mg} / \mathrm{m}^{2}\right.$ body surface area) was compared to placebo ( $5 \%$ dextrose in water) administered via intravenous infusion of $30 \mathrm{ml}$ over 10 minutes. This was followed after 15 minutes by application of 83 seconds of laser light at $689 \mathrm{~nm}$ delivered 50 joules $/ \mathrm{cm}^{2}$ at an intensity of $600 \mathrm{~mW} / \mathrm{cm}^{2}$ using a spot size with a diameter 1000 microns larger than the greatest linear dimension of the $\mathrm{CNV}$ lesion.

Participants in TAP 1999 were reviewed every three months when visual acuity was measured and repeat fluorescein angiography performed. If the trial surgeon judged a recurrence of the membrane to be present or a persistence of the previous lesion, then repeat treatment was undertaken. In the phase one and two studies it was concluded that up to five treatments were necessary to stabilise the situation (Miller 1999; Schmidt-Erfurth 1999). In the first year a mean of 3.4 treatments were delivered to the treatment group and 3.7 to the control group. In the second year a mean of 2.2 treatments were delivered to the treatment group and 2.8 to the controls group.

Visual acuity was measured in VIP 2001 at 12 and 24 months. The report of the study did not indicate the mean number of treatments delivered for all participants. However, in the subgroup with occult CNV (76\% of all participants) 3.1 treatments were given in the treatment group and 3.5 in the control group. In the second year, 1.8 and 2.4 treatments were given in the verteporfin and control groups respectively.

\section{METHODOLOGICALQUALITY}

Both TAP 1999 and VIP 2001 were high quality studies with a very similar study design.

Allocation of treatment group was by opaque serially-numbered sealed envelopes and was stratified by clinical centre. The baseline characteristics of the participants by treatment group were published. The groups were well balanced with respect to a variety of demographic and clinical variables. Only one eye per person was treated.
Reasonable attempts were made to mask the ophthalmologist, participant, vision examiner and Photograph Reading Center personnel to the treatment assigned. As verteporfin and placebo were different colours (green versus colourless), the solutions and the intravenous tubing were covered with foil. The fundus appearance does not change during treatment to indicate whether verteporfin or placebo had been infused. There is no other physical evidence of treatment as verteporfin dye is excreted in the faeces and does not cause any colour change, and does not alter the colour of the skin or urine. It was therefore unlikely that participants were aware of their treatment status. In TAP 1999 the study investigators reported two instances where the participants were unmasked, and four cases where the ophthalmologists were unmasked, having noted a green solution.

Rates of follow up were high in both studies. In TAP $199994 \%$ were seen at 12 months and $87 \%$ at 24 months. Follow up was similar between the two treatment groups. The analysis was intention-to-treat and subgroup analyses were planned a priori (Bressler $\mathrm{N}$, personal communication). In VIP $200193 \%$ were seen at 12 months and $86 \%$ at 24 months. All participants were included in the analyses and missing values were imputed using the method of last observation carried forward.

\section{R E S U L T S}

The realistic aim of photodynamic therapy is to slow progression of age-related macular degeneration, not to produce normal vision. Outcomes are therefore expressed as risks of a poor outcome, rather than as improvements in vision. All results are based on the comparison of people randomised to receive verteporfin with those randomised to receive placebo (control).

\section{Overall analysis}

\section{Loss of three or more lines of visual acuity}

A total of 948 participants from TAP 1999 and VIP 2001 were included in the meta-analysis. At 12 months the pooled relative risk of losing three or more lines of visual acuity was $0.80(95 \%$ confidence interval (CI) 0.70 to 0.91) (see Graphs, Comparison 01.01). The relative risk reduction was therefore $0.20(95 \% \mathrm{CI}$ 0.09 to 0.30 ). This analysis was done using a fixed-effect model. A random-effects model gave a non-significant result, largely because it placed more weight on the VIP study (pooled relative risk 0.82 (95\% CI 0.64 to 1.04 ).

At 24 months the pooled relative risk was 0.77 (95\% CI 0.69 to 0.87) (see Graphs, Comparison 01.02) and the relative risk reduction was therefore 0.23 ( $95 \%$ CI 0.13 to 0.31 ). The randomeffects model gave a similar result.

\section{Loss of six or more lines of visual acuity}

At 12 months the relative risk of losing six or more lines of visual acuity was 0.62 (95\% CI 0.44 to 0.87 ) (see Graphs, Comparison 01.03) (TAP 1999 only, data not reported for VIP 2001). The 
relative risk reduction was therefore 0.38 ( $95 \%$ CI 0.13 to 0.56 ). At 24 months the pooled relative risk was 0.62 (95\% CI 0.50 to 0.76) (see Graphs, Comparison 01.04). The relative risk reduction was 0.38 (95\% CI 0.24 to 0.50$)$.

\section{Mean number of lines lost}

In TAP 1999 the mean number of lines of vision lost at 12 months was 2.2 in the intervention group and 3.5 in the control group. The difference was 1.3 with fewer lines lost in the intervention group. The $\mathrm{P}$ value for the difference in the mean number of lines lost was reported as $\mathrm{P}<0.001$ (Wilcoxon rank sum test). At 24 months the mean number of lines of vision lost was 2.7 in the intervention group and 3.9 in the control group, a difference of 1.2 lines $(\mathrm{P}<0.001)$. The standard deviations for the mean numbers of lines lost were not reported and therefore we could not calculate confidence intervals.

Data on mean number of lines lost for the whole VIP 2001 study group were not reported.

\section{Subgroup analyses}

Subgroup data were available only for the outcome 'loss of three or more lines of visual acuity' in TAP 1999 but for both outcomes (loss of three lines and loss of six lines) in VIP 2001.

\section{Evidence of occult choroidal neovascularisation}

In TAP 1999 the relative risks of losing three or more lines of visual acuity at 12 months were 0.90 if occult choroidal neovascularisation (CNV) was present (95\% CI 0.73 to 1.11$)$ and 0.34 if occult CNV was absent ( $95 \%$ CI 0.22 to 0.51 ). At 24 months, the relative risks were $0.88(95 \% \mathrm{CI} 0.74$ to 1.04$)$ and $0.42(95 \% \mathrm{CI}$ 0.30 to 0.60 ) respectively. The test for effect modification between these two subgroups was significant. Neither the $95 \%$ confidence intervals nor the $99 \%$ confidence intervals for these two subgroups overlap.

\section{Lesion area composed of classic choroidal neovascularisation} In TAP 1999 the proportion of the lesion comprised of classic $\mathrm{CNV}$ was estimated as $0 \%$; greater than $0 \%$ but less than $50 \%$; greater than $50 \%$. The proportion was unknown in four participants (three in the treatment group and one in the control group). The subgroup analyses were therefore based on a total of 399 eyes.

In VIP 2001 the majority of the participants (76\%) had "occult with no classic CNV". An additional 56 eyes had some classic $\mathrm{CNV}$ (less than $50 \%$ but greater than $0 \%$ as above). Only 19 eyes had predominantly classic CNV.

The pooled relative risks for losing three or more lines of visual acuity at 12 months for the group with $0 \% \mathrm{CNV}$ was 0.84 (95\% CI 0.68 to 1.04). Results for three or more lines lost at 12 months were not reported for the other two subgroups in the VIP 2001 study. In TAP 1999 the relative risk for losing three or more lines of visual acuity at 12 months in people with more than $0 \%$ but less than $50 \% \mathrm{CNV}$ was 0.99 (95\% CI 0.76 to 1.29$)$ and 0.54 for greater than $50 \% \mathrm{CNV}$ (95\% CI 0.40 to 0.71 ) (see Graphs, Comparison 01.05 ).
At 24 months the pooled relative risks for losing three or more lines of visual acuity were 0.77 (95\% CI 0.64 to 0.92$), 0.93$ (95\% CI 0.77 to 1.14$)$ and 0.60 (95\% CI 0.48 to 0.75$)$ respectively (see Graphs, Comparison 01.06).

These results suggest there was a reduction in the risk of loss of vision when classic CNV was absent or when greater than $50 \%$ of the lesion was comprised of classic CNV. However there was very little reduction in risk when between $0 \%$ and $50 \%$ of the lesion was comprised of classic CNV. However the test for effect modification between these three subgroups was not statistically significant $(\mathrm{P}=0.066)$.

\section{Number needed to treat}

We calculated the numbers needed to treat (NNTs) to prevent one person losing three or more lines and, where possible, one person losing six or more lines of vision. These NNTs are derived from the study population, that is, people with subfoveal CNV and a baseline visual acuity of between 20/40 and 20/200 with approximately five treatments over two years.

The NNT to prevent one person losing three or more lines of vision at 24 months was 7.1 (95\% CI 4.8 to 12.5 ). The NNT to prevent one person losing six or more lines of vision at 24 months was 7.1 (95\% CI 5.0 to 12.5$)$.

\section{Other primary outcomes}

\section{Contrast sensitivity}

This outcome from the TAP trial was reported by Rubin 2002 . This was measured in participants at baseline and at three-monthly intervals after refraction and measurement of best-corrected visual acuity. Contrast sensitivity was measured using the Pelli Robson chart (no. 7002251 Clement Clarke, Columbus Ohio). The measurements were made using a standard protocol and illumination and outcomes were categorised in terms of more than 6 or more than 15 letters lost since baseline. A higher proportion of those treated with placebo lost both more than 6 and 15 letters of contrast sensitivity at 12 and 24 months. The relative risk of losing 6 lines of contrast sensitivity by 24 months was 0.47 ( $95 \%$ confidence interval (CI) 0.37 to 0.60 ) in the PDT group compared to placebo (see Graphs, Comparison 01.07). For 15 letters the relative risk was 0.58 (95\% CI 0.34 to 0.98) (see Graphs, Comparison 01.08).

\section{Central visual field function}

This was reported by Schmidt-Erfurth (Schmidt-Erfurth 2004) for 46 participants of the TAP trial based in Germany. Participants in this centre had various additional investigations reported including Scanning Laser Ophthalmoscopic perimetry of the macular in order to measure the size of the central scotoma in treated and placebo groups. This was reported as mean area in $\mathrm{mm}^{2}$ The mean area of the absolute scotoma increased in both groups but significantly more the placebo arm $\left(2.5 \mathrm{~mm}^{2}\right.$ baseline to $7.3 \mathrm{~mm}^{2}$ at 24 months in the treated group compared to $2.7 \mathrm{~mm}^{2}$ at baseline to $31.5 \mathrm{~mm}^{2}$ at 24 months in the placebo group). Similar findings 
were reported for differences in the increase in size of the relative scotoma between groups. These differences were reported as statistically significant at the level of $\mathrm{P}<0.001$ though neither standard errors of these means nor $95 \%$ confidence intervals are provided.

\section{Secondary outcomes}

\section{Neovascular membrane morphology}

Schmidt-Erfurth's group also reported on the outcome of Confocal Indocyanine Green Angiography on her subgroup of the TAP trial participants in Germany (Schmidt-Erfurth 2003); in this case outcomes were reported on 60 participants. It is not clear why there is a discrepancy between the 60 participants in this analysis and 46 undergoing measurement of central scotoma as described above. Presumably 14 patients did not have SLO perimetry but did have ICG angiography.

This paper reports outcomes in terms of the mean size of the neovascular membrane in $\mathrm{mm}^{2}$. Forty eyes received PDT and 20 received placebo. Baseline mean areas of ICG leakage were 3.9 $\mathrm{mm}^{2}$ for the PDT group and $2.8 \mathrm{~mm}^{2}$ for the placebo eyes. This reduced to $3.0 \mathrm{~mm}^{2}$ in the treated group at 24 months compared to a growth to $9.6 \mathrm{~mm}^{2}$ in placebo eyes. This difference is reported as highly significant by $\mathrm{P}$ value $(=0.008)$ but no standard errors or confidence limits are provided apart from graphically represented error bars which are not specified in the legend.

\section{Quality of life}

Evidence of efficacy as described above has still not been substantiated by any quality of life outcomes reported from the TAP or VIP trials.

\section{Adverse effects}

More information on this has become available for this update. In particular the risk of severe and profound visual loss has been better estimated. This has been provided by two reports from the TAP and VIP investigators (Arnold 2004; Azab 2004) and a large phase 4 open-label study reporting on the outcomes of verteporfin PDT in 4435 patients called the VAM study (Bessler 2004).

Arnold 2004 focuses on the occurrence of acute severe visual acuity decrease (ASVAD). This was defined as at least a 20 letter loss (equivalent to four lines) within seven days after treatment. Even though this paper reports this outcome from two RCTs they describe the study as an observational case series and a fairly detailed account is given of 15 events in 14 eyes. One of these was later judged as unlikely to be due to PDT. All but two events occurred shortly after the first treatment and only in the treated arm. Three of these events occurred in the TAP trial and ten in the VIP. All 13 events occurred within three days of treatment. The absolute risk difference for both studies is 0.02 (95\% confidence interval 0.01 to 0.03) (see Graphs, Comparison 01.09). The number needed to harm (NNH) is estimated to be about 50 (range 30 to 100). That is one eye will experience ASVAD in 50 treatments.

Azab 2004 provides these data in the context of all other adverse events reported for the two trials. This report is described as a meta-analysis though data are only combined for the two trials for systemic side effects. The authors found that only visual disturbances including ASVAD, injection site reactions, photosensitivity reactions and infusion-related back pain occurred with greater frequency in the treated participants.

The VAM study (Bessler 2004) reports on outcomes from a larger number of patients recruited from 222 centres in North America (10 times the number in TAP) between September 1999 and June 2000 when the verteporfin became commercially available. Maximum follow up was therefore nine months. About half the study population had six months follow up. This study provides further information on the risk of adverse events outside an RCT setting but as this is an open label study with no comparator group; relative risks or risk differences (and hence $\mathrm{NNH}$ ) cannot be calculated. However, it is assumed that, as in TAP and VIP, no events would have occurred in an untreated arm, the risk becomes the same as the risk difference. Of the 4435 enrolled 115 (2.6\%) reported abnormal or decreased vision of whom 25 experienced ASVAD (0.6\%) (NNH@166). ASVAD is thought to be caused by bleeding under the retina after PDT. One series from the Wilmer (Do 2004) reports this outcome in 52 patients but unfortunately the denominator was not given (the overall number of persons and eyes receiving PDT). Vision loss can be profound is this group and data from TAP and VIP suggest it may be more likely to occur in people with better initial visual acuity.

Reports of visual disturbance (reports of "abnormal vision", "decreased vision" and visual field defect) occurred in one in every four people taking part in the TAP 1999 and VIP 2001 studies. This is perhaps unsurprising as participants had neovascular AMD. However, people treated with verteporfin were more likely to report visual disturbance (pooled relative risk 1.61, 95\% CI 1.24 to 2.09) (see Graphs, Comparison 01.10). Presumably this visual disturbance must have been reasonably transient as visual outcomes at 12 and 24 months were better in the treatment group. $2.4 \%$ of people treated with verteporfin experienced infusion-related back pain and $2.4 \%$ had photosensitivity reactions. Problems with the injection site occurred in $13.1 \%$ of people treated with verteporfin compared to $5.6 \%$ people in the control group. Few allergic reactions were seen and these were equally likely in treatment and control groups.

\section{Economic outcomes}

No economic analyses have been reported from either TAP or VIP.

\section{DISCUSSION}

The absence to date of any effective treatment for neovascular agerelated macular degeneration (except for the few in whom laser photocoagulation works) means that there will be intense interest in photodynamic therapy for the many millions of sufferers of the disease worldwide. Unfortunately photodynamic therapy, 
like photocoagulation, can be effective only during the proliferative stage of the disease while the neovascular process is active. It cannot have any effect once sight is lost and the scarring process is complete. Therefore, like so many other degenerative processes of the neuroretina, nothing can be done to restore function once the damage is done. Most sufferers of the condition have established sight loss and, for these, the publicity surrounding the launch of Visudyne (verteporfin) will have raised false hopes. However, this review indicates that for people with active neovascular disease photodynamic therapy can prevent vision loss. This is corroborated by additional outcome measures such as contrast sensitivity, size of central scotoma and neovascular membrane dimensions.

A key question is how long the effect of treatment will last and whether repeated treatments would be required in the longer term. This review indicates that treatment benefits last for at least two years. An open-label extension of the TAP 1999 study indicated that vision outcomes remained relatively stable from 24 to 48 months (TAP 2002). There have been no further reports of longer term outcomes.

Another important issue is how many presenting patients will benefit from photodynamic therapy. In addition to the problem of accessing specialist services in time, there is the question of the proportion of lesions that will actually be treatable. The evidence reported here clearly suggests that purely classic neovascular membranes do well. Subgroup analysis of the TAP 1999 study suggested that photodynamic therapy is not effective when occult $\mathrm{CNV}$ is present. Occult vessels mean that the extent of the membrane cannot be clearly defined and so it is not surprising that treatment is found to be less effective because the laser cannot be aimed at the entire membrane. However, the VIP 2001 study recruited mostly patients with occult neovascularisation and demonstrated a treatment benefit of photodynamic therapy at 12 and 24 months. Pooled analysis of the TAP 1999 and VIP 2001 studies in this review showed no statistically significant difference in treatment effects in subgroups defined by the presence or absence of classic CNV. This observation has been noted by other authors. For example, Meads 2004 casts serious doubt on the validity of the subgroup analyses.

Subsequent reports of "exploratory" analyses (presumably not specified a priori) have been published from the TAP trials (Bressler 2002) and from the TAP and VIP trials (Blinder 2003) which find only lesion size (the smaller lesions do better) and poorer presenting acuity (perhaps less vision to lose) were predictors of better outcome. One other report from TAP (Bressler 2004) examined the natural history of minimally classic lesions which had a poorer outcome in the TAP trial treated group. Of the 207 randomised to the placebo group 98 had minimally classic lesions of which 39 progressed to become predominantly classic (21 of these within three months). The suggestion here is that it might be advisable to wait for minimally classic lesions to progress to become predominantly classic so that potential effectiveness of PDT might be greater. The authors imply that this need not necessarily be at the expense of allowing the lesion to become very large or indeed the vision to deteriorate.

We are not told in the available reports the extent to which clinicians and indeed the trial Photograph Reading Center personnel were able to agree about the subgroup classification of classic or occult lesions. It is likely that there is much variation in opinion on this. The necessary skill to report on fluorescein angiograms and recognise different lesion types is highly refined. Most experts assert that stereo images are required to be able to locate the position in depth of staining or fluorescein leaks. Stereophotography requires either a dedicated camera equipped to take simultaneous stereo images or a skilled photographer who takes sequential images slightly laterally displaced from one another, providing a nonsimultaneous or pseudo-stereo image. However, the guidelines for reporting angiograms and data on interobserver agreement have now been published for the TAP and VIP trials (Barbazetto 2003). A lot of detail is given on reporting guidelines but the information on agreement is somewhat brief though reported kappa values for the main subgroup criteria were good. This was based on a $10 \%$ subsample of graded photographs. Another independent study has reported on agreement within and between 16 different specialists in Germany (Holz 2003) for the same angiographic criteria as for TAP and VIP. Agreement was not quite so good for both intra and interobserver agreement as for the reporting centre for the trials but was acceptable nevertheless.

The natural history of the growth of subretinal membranes varies from individual to individual. They may be aggressive and rapidly growing or indolent. This is the kind of individual factor that will influence the likelihood of a patient being in a position to benefit from this treatment. The trial report does not comment on the proportion of participants presenting to the trial centres that had treatable lesions. The verbal estimate from one trialist was approximately $25 \%$ and from another expert between $5 \%$ and $7 \%$. This is of crucial importance in estimating the impact of this new treatment on healthcare budgets.

Age-related macular degeneration is a bilateral disease although one eye is usually affected before the other. With a lesion present in one eye, the annual cumulative incidence of a lesion in the second eye is estimated to be about $15 \%$. Clinicians now commonly advise patients with a lesion in one eye to be watchful for the onset of symptoms in the second eye and to present as soon as those symptoms are noticed to improve the chances of catching the lesion in the second eye in time. This often entails the provision of an Amsler grid, a simple chart on which a number of gridlines are printed around a central fixation spot. The patient is instructed to examine the grid and to look for focal distortion of the lines in the grid which would indicate local elevation of the retina as a result of the growth of an underlying membrane. This strategy offers the best hope of saving sight with this new treatment at least in places where access to a qualified ophthalmologist can be slow. 
It should also be recalled that this treatment does not restore sight but rather prevents further deterioration. Sustaining numerous assessments which involve relatively invasive treatments may have an adverse effect on the patient. Without patient-orientated outcomes in these trials we cannot comment on the patient's perspective on the experience of Visudyne therapy. It is likely that in most cases, especially where loss of sight of the second eye is threatened, patients will be willing to undergo all the necessary interventions, even when the probability of success is small.

Quality of life outcomes have been independently reported in a cohort of individuals treated with PDT and followed for one year (Armbrecht 2004). There was no comparator group. At 12 months participants were less anxious and more independent than baseline though there was a significant deterioration in more vision-related tasks.

Adverse effects occurred infrequently with the exception of the rather vague "visual disturbance" which affected more people in the verteporfin group compared to the control group. However, this was not reflected in the visual acuity outcomes. Infusionrelated back pain occurred in $2.4 \%$ which is substantially lower than in some other studies. For example, in a series of 250 people treated with verteporfin $9.6 \%$ experienced verteporfin-associated pain, most of which was back pain (Borodoker 2002). It is now clear that acute severe visual acuity decrease is a relatively small but serious risk of poor outcome of treatment. This review estimates this risk to be approximately one in 50 patients.

The trials included in this review appear to have been performed to high standards and were closely supervised by the Food and Drugs Administration of the USA. Both trials were sponsored by the manufacturers of the drug (CIBA Vision and Novartis Ophthalmics) and declared potential conflicts of interest exist for a number of the trialists who hold interests in the manufacturer of the laser technology. This makes detailed scrutiny of reports of the trial essential. Of concern are the numerous protocol revisions that were registered with the Institutional Review Bodies throughout the study and after completion of follow up. Although we have not yet had access to the main protocol or to the revisions, a CIBA representative has assured us that the changes were not substantive and, in particular, that there were no changes to the a priori determinants of the primary outcomes.

New reviews have not drawn any conflicting conclusions or any additional evidence. In particular, the review commissioned by the National Health Service's Research and Development Health Technology Assessment Programme on behalf of the National Institute of Clinical Excellence (NICE) in the UK (accessible at http://www.nice.org.uk) was in accordance with the findings of our review but went on to perform a detailed cost and cost-utility analysis. They concluded through economic modelling that the benefits of PDT with verteporfin at two years were "at best at the margins of what is generally considered to be an efficient use of health care resources".

Another paper from Australia (Hopley 2004) examined cost-utility for PDT for predominantly classic neovascular AMD using data from the TAP trial in two cost-utility models for two case scenarios. They conclude that as the only available treatment for some forms of neovascular AMD, PDT can be considered moderately cost effective for those with reasonable acuity but less so for those with poorer presenting vision. These conclusions depend upon the validity of the subgroup analyses of the TAP trial and there must be some concern that one of the conclusions of the trialists post hoc analyses that those with poorer presenting vision fare better in terms of numbers of lines of visual acuity lost.

The NICE review concluded that there was still much uncertainty about the effectiveness of this treatment. In the face of enormous pressure to provide something that might work when nothing else is available, provision of service conditional on close monitoring of outcomes is a pragmatic approach, though implementation of this policy is difficult.

\section{A U THORS, CONCLUSIONS}

\section{Implications for practice}

This review provides evidence that photodynamic therapy in people with classic and occult choroidal neovascularisation due to agerelated macular degeneration is probably effective in preventing visual loss though the size of the effect remains in doubt. On the basis of existing evidence, approximately seven people need to be treated with an average of five treatments over two years to prevent one person losing three or more lines of visual acuity. One in every 50 treated patients will have an acute severe loss of vision in the treated eye. For an expensive treatment there are questions about the cost-utility and indeed opportunity cost for health services, especially when resources are limited.

Two trials were included in this review. Both trials were performed by the same investigators using largely the same clinical centres and funded by manufacturers of verteporfin. As for all new technology, outcomes and potential adverse effects need to be monitored when introduced into clinical practice and this recommendation has been implemented in the UK by the establishment of a national cohort study to monitor outcomes of verteporfin PDT according to NICE guidelines in the NHS.

There are major implications for health services, both in terms of potential expenditure and organisation, if photodynamic therapy is to be introduced. Where referral to an ophthalmologist is through a primary care network, facilities for the recognition of this condition in its early stages are needed. There is potential for an enormous increase in referral of people with early age-related maculopathy for assessment, in case an early treatable lesion is 
present. This could swamp already overstretched facilities at the secondary care level. Extra resources will be required at the secondary care level to manage increased referrals, for the necessary technology to diagnose treatable lesions and to deliver treatment.

\section{Implications for research}

Further independent trials of verteporfin are required to establish that the effects seen in this study are consistent and to examine important issues not yet addressed, particularly relating to quality of life and cost.

A similar recommendation was made by the authors commissioned for NICE for publicly-funded pragmatic trials with economic and vision-related quality of life outcomes over a longer time scale. To our knowledge no such studies are underway. Some commentators argue that technology is progressing at a pace that will render such studies irrelevant. New interventions for AMD, particularly those based on drugs active against Vascular Endothelial Growth Factor, show some promise and there is speculation that the role of PDTbased treatments will be short-lived.

Descriptive epidemiology on the population at risk and the numbers likely to benefit from these kinds of interventions remains essential to estimate the impact of these new treatments on health service resources and the well being of the ageing population of more affluent countries with a life-expectancy sufficient to render AMD a significant public health concern. A particular concern remains that people in need of treatment can access it equitably and in time. Health services research of this nature and surveillance for rare but severe adverse effects is required.

\section{POTENTIALCONFLICTOF I N T E R E S T}

None known.

\section{ACKNOWLEDGEMENTS}

The Cochrane Eyes and Vision Group developed and executed the electronic searches. We would like to thank Neil Bressler, Simon Harding and Javed Bhatti (CIBA Vision) for providing information about the TAP study. Usha Chakravarthy (Queens University, Belfast) and Bob Thompson (Macular Disease Society) provided useful comments on the review.

\section{SOURCESOFSUPPORT}

\section{External sources of support}

- No sources of support supplied

Internal sources of support

- Moorfields Eye Hospital NHS Trust UK

\section{R E F E R E N C E S}

\section{References to studies included in this review}

TAP 1999 \{published and unpublished data\}

Rubin GS, Bressler NM, the Treatment of Age-Related Macular Degeneration with Photodynamic Therapy (TAP) Study Group. Effects of verteporfin therapy on contrast sensitivity: results from the treatment of age-related macular degeneration with photodynamic therapy (TAP) investigation - TAP report no. 4. Retina 2002;22(5):53644.

* Treatment of Age-related Macular Degeneration With Photodynamic Therapy (TAP) Study Group. Photodynamic therapy of subfoveal choroidal neovascularization in age-related macular degeneration with verteporfin: One-year results of 2 randomized clinical trials - TAP report. Archives of Ophthalmology 1999;117(10):1329-45. [MedLine: 10532441].

Treatment of Age-related Macular Degeneration With Photodynamic Therapy (TAP) Study Group. Photodynamic therapy of subfoveal choroidal neovascularization in age-related macular degeneration with verteporfin: Two-year results of 2 randomized clinical trials - TAP report 2. Archives of Ophthalmology 2001;119(2):198-207. [MedLine: 11176980].

Treatment of Age-Related Macular Degeneration with Photodynamic Therapy (TAP) Study Group. Verteporfin therapy for sub- foveal choroidal neovascularization in age-related macular degeneration: three-year results of an open-label extension of 2 randomized clinical trials - TAP report no 5. Archives of Ophthalmology 2002;120 (10):1307-14. [MedLine: 12365909].

VIP 2001 \{published data only\}

Bressler NM. Verteporfin therapy of subfoveal choroidal neovascularization in age-related macular degeneration: two-year results of a randomized clinical trial including lesions with occult with no classic choroidal neovascularization - Verteporfin In Photodynamic Therapy Report 2. American Journal of Ophthalmology 2002;133(1):1689. [MedLine: 11755871].

* Verteporfin in Photodynamic Therapy Study Group. Verteporfin therapy of subfoveal choroidal neovascularization in age-related macular degeneration: two-year results of a randomized clinical trial including lesions with occult with no classic choroidal neovascularization - Verteporfin in Photodynamic Therapy Report 2. American Journal of Ophthalmology 2001;131(5):541-60. [MedLine: 11336929].

\section{References to studies excluded from this review}

\section{Schmidt-Erfurth 1999}

Schmidt-Erfurth U, Miller JW, Sickenberg M, Laqua H, Barbazetto I, Gragoudas ES, et al. Photodynamic therapy with verteporfin for 
choroidal neovascularisation caused by age-related macular degeneration. Results of retreatment in a phase 1 and 2 study. Archives of Ophthalmology 1999;117(9):1177-87. [MedLine: 10496389].

\section{References to ongoing studies \\ ADD-V}

Addition of an anti-inflammatory called Voltaren Ophthalmic ${ }^{\circledR}$. Ongoing study Starting date of trial not provided. Contact author for more information.

Japan

Visudyne for CNV due to AMD. Ongoing study Results expected at end 2003.

\section{VALIO}

Altered light treatment using delayed light after Visudyne in occult AMD. Ongoing study Starting date of trial not provided. Contact author for more information.

VER

Visudyne in Early Retreatment Phase IIIB clinical trial. Ongoing study Results expected at end 2003.

VIM

Visudyne in Minimally Classic study. Ongoing study Starting date of trial not provided. Contact author for more information.

VIO

Visudyne therapy in Occult Phase III trial. Ongoing study Starting date of trial not provided. Contact author for more information.

\section{Additional references}

Armbrecht 2004

Armbrecht AM, Aspinall PA, Dhillon B. A prospective study of visual function and quality of life following PDT in patients with wet age related macular degeneration. British Journal of Ophthalmology 2004; 88(10):1270-3.

\section{Arnold 2004}

Arnold JJ, Blinder KJ, Bressler NM, Bressler SB, Burdan A, Haynes L, et al. Acute severe visual acuity decrease after photodynamic therapy with verteporfin: case reports from randomized clinical trials-TAP and VIP report no. 3. American Journal of Ophthalmology 2004;137 (4):683-96.

Azab 2004

Azab M, Benchaboune M, Blinder KJ, Bressler NM, Bressler SB, Gragoudas ES, et al. Verteporfin therapy of subfoveal choroidal neovascularization in age-related macular degeneration: meta-analysis of 2-year safety results in three randomized clinical trials: Treatment Of Age-Related Macular Degeneration With Photodynamic Therapy and Verteporfin In Photodynamic Therapy Study Report no. 4. Retina 2004;24(1):1-12.

Barbazetto 2003

Barbazetto I, Burdan A, Bressler NM, Bressler SB, Haynes L, Kapetanios AD, et al. Photodynamic therapy of subfoveal choroidal neovascularization with verteporfin: fluorescein angiographic guidelines for evaluation and treatment-TAP and VIP report No. 2. Archives of Ophthalmology 2003;121(9):1253-68.

Bessler 2004

Bessler NM, VAM Study Writing Committee. Verteporfin therapy in age-related macular degeneration (VAM): an open-label multicenter photodynamic therapy study of 4,435 patients. Retina 2004;24(4): $512-20$.

Blinder 2003

Blinder KJ, Bradley S, Bressler NM, Bressler SB, Donati G, Hao Y, et al. Effect of lesion size, visual acuity, and lesion composition on visual acuity change with and without verteporfin therapy for choroidal neovascularization secondary to age-related macular degeneration: TAP and VIP report no. 1. American Journal of Ophthalmology 2003; 136(3):407-18.

Borodoker 2002

Borodoker N, Spaide RF, Maranan L, Murray J, Freund KB, Slakter JS, et al. Verteporfin infusion-associated pain. American Journal of Ophthalmology 2002;133(2):211-4.

Bressler 2002

Bressler NM, Arnold J, Benchaboune M, Blumenkranz MS, Fish GE, Gragoudas ES, et al. Verteporfin therapy of subfoveal choroidal neovascularization in patients with age-related macular degeneration: additional information regarding baseline lesion composition's impact on vision outcomes-TAP report No. 3. Archives of Ophthalmology 2002;120(11):1443-54.

\section{Bressler 2004}

Bressler SB, Pieramici DJ, Koester JM, Bressler M. Natural history of minimally classic subfoveal choroidal neovascular lesions in the treatment of age-related macular degeneration with photodynamic therapy (TAP) investigation: outcomes potentially relevant to management--TAP report No. 6. Archives of Ophthalmology 2004;122(3): $325-9$.

Do 2004

Do DV, Bressler NM, Bressler SB. Large submacular hemorrhages after verteporfin therapy. American Journal of Ophthalmology 2004; 137(3):558-60.

\section{Higgins 2005a}

Higgins JPT, Green S, editors. Locating and selecting studies for reviews. Cochrane Handbook for Systematic Reviews of Interventions 4.2.4 [updated March 2005]; Section 5. The Cochrane Library, Issue 2, 2005. Chichester, UK: John Wiley \& Sons, Ltd.

\section{Higgins 2005b}

Higgins JPT, Green S, editors. Assessment of quality. Cochrane Handbook for Systematic Reviews of Interventions 4.2.4 [updated March 2005]; Section 6. The Cochrane Library, Issue 2, 2005. Chichester, UK: John Wiley \& Sons, Ltd.

\section{Holz 2003}

Holz FG, Jorzik J, Schutt F, Flach U, Unnebrink K. Agreement among ophthalmologists in evaluating fluorescein angiograms in patients with neovascular age-related macular degeneration for photodynamic therapy eligibility (FLAP-study). Ophthalmology 2003;110 (2):400-5.

Hopley 2004

Hopley C, Salkeld G, Mitchell P. Cost utility of photodynamic therapy for predominantly classic neovascular age related macular degeneration. British Journal of Ophthalmology 2004;88(8):982-7.

\section{Meads 2004}

Meads C, Hyde C. Photodynamic therapy with verteporfin is effective, but how big is its effect? Results of a systematic review. British Journal of Ophthalmology 2004;88(2):212-7. 
Miller 1999

Miller JW, Schmidt-Erfurth U, Sickenberg M, Pournaras CJ, Laqua $\mathrm{H}$, Barbazetto I, et al. Photodynamic therapy with verteporfin for choroidal neovascularisation caused by age-related macular degeneration. Results of a single treatment in a phase 1 and 2 study. Archives of Ophthalmology 1999;117(9):1161-73.

\section{MPS 1994}

Macular photocoagulation study group. Laser photocoagulation for juxtafoveal choroidal neovascularization: five year results from randomized clinical trials. Archives of Ophthalmology 1994;112(4):500

\section{Rubin 2002}

Rubin GS, Bressler NM, Treatment of Age Related Macular Degeneration with Photodynamic therapy TAP Study Group. Effects of verteporfin therapy on contrast on sensitivity: Results From the Treatment of Age-Related Macular Degeneration With Photodynamic Therapy (TAP) investigation-TAP report No 4. Retina 2002;22(5): 536-44.

Schmidt-Erfurth 2003

Schmidt-Erfurth UM, Michels S. Changes in confocal indocyanine green angiography through two years after photodynamic therapy with verteporfin. Ophthalmology 2003;110(7):1306-14

\section{Schmidt-Erfurth 2004}

Schmidt-Erfurth UM, Elsner H, Terai N, Benecke A, Dahmen G, Michels SM. Effects of verteporfin therapy on central visual field function. Ophthalmology 2004;111(5):931-9.

\section{TAP 2002}

Treatment of Age-Related Macular Degeneration with Photodynamic Therapy (TAP) Study Group. Verteporfin therapy for subfoveal choroidal neovascularization in age-related macular degeneration: three-year results of an open-label extension of 2 randomized clinical trials - TAP report no 5. Archives of Ophthalmology 2002;120 (10): $1307-14$

Woodburn 2002

Woodburn KW, Engelman CJ, Blumenkranz MS. Photodynamic therapy for choroidal neovascularization: a review. Retina 2002;22 (4):391-405.

* Indicates the major publication for the study

T A B LE S

\section{Characteristics of included studies}

\begin{tabular}{|c|c|}
\hline Study & TAP 1999 \\
\hline Methods & Randomised controlled trial: one eye per patient was randomised in a 2:1 (treatment:control) ratio \\
\hline Participants & $\begin{array}{l}609 \text { people with subfoveal CNV lesions caused by AMD with evidence of classic CNV and best corrected } \\
\text { acuity of approximately } 20 / 40 \text { to } 20 / 200\end{array}$ \\
\hline Interventions & $\begin{array}{l}\text { Photodynamic therapy following verteporfin injection versus photodynamic therapy following intravenous } \\
5 \% \text { dextrose }\end{array}$ \\
\hline Outcomes & Visual acuity at 12 and 24 months \\
\hline \multicolumn{2}{|l|}{ Notes } \\
\hline Allocation concealment & A - Adequate \\
\hline Study & VIP 2001 \\
\hline Methods & $\begin{array}{l}\text { Randomised controlled trial: one eye per patient was enrolled. Randomisation in sealed envelopes stratified } \\
\text { by clinical centre. }\end{array}$ \\
\hline Participants & 339 people with subfoveal CNV caused by AMD \\
\hline Interventions & $\begin{array}{l}\text { Photodynamic therapy following verteporfin injection versus photodynamic therapy following intravenous } \\
5 \% \text { dextrose }\end{array}$ \\
\hline Outcomes & $\begin{array}{l}\text { Visual acuity at } 12 \text { and } 24 \text { months } \\
\text { Secondary outcomes include contrast sensitivity and changes in angiographic outcomes }\end{array}$ \\
\hline Notes & Randomised 2:1 to verteporfin treatment \\
\hline Allocation concealment & A- Adequate \\
\hline $\begin{array}{l}\text { AMD - age-related macular } \\
\text { CNV - choroidal neovascula }\end{array}$ & $\begin{array}{l}\text { degeneration } \\
\text { risation }\end{array}$ \\
\hline
\end{tabular}




\section{Characteristics of excluded studies}

\begin{tabular}{ll} 
Study & Reason for exclusion \\
\hline Schmidt-Erfurth 1999 & Non-randomised open-label phase I and II trial \\
\hline
\end{tabular}

\section{Characteristics of ongoing studies}

\begin{tabular}{|c|c|}
\hline Study & ADD-V \\
\hline Trial name or title & Addition of an anti-inflammatory called Voltaren Ophthalmic ${ }^{\circledR}$ \\
\hline \multicolumn{2}{|l|}{ Participants } \\
\hline \multicolumn{2}{|l|}{ Interventions } \\
\hline \multicolumn{2}{|l|}{ Outcomes } \\
\hline \multicolumn{2}{|l|}{ Starting date } \\
\hline \multirow{2}{*}{\multicolumn{2}{|c|}{$\begin{array}{l}\text { Contact information } \\
\text { Notes }\end{array}$}} \\
\hline & \\
\hline Study & Japan \\
\hline Trial name or title & Visudyne for $\mathrm{CNV}$ due to AMD \\
\hline \multicolumn{2}{|l|}{ Participants } \\
\hline \multicolumn{2}{|l|}{ Interventions } \\
\hline \multicolumn{2}{|l|}{ Outcomes } \\
\hline Starting date & Results expected at end 2003 \\
\hline Contact information & Nic Gwatkin, Head of Marketing, Novartis Ophthalmics \\
\hline \multicolumn{2}{|l|}{ Notes } \\
\hline Study & VALIO \\
\hline Trial name or title & Altered light treatment using delayed light after Visudyne in occult AMD \\
\hline \multicolumn{2}{|l|}{ Participants } \\
\hline \multicolumn{2}{|l|}{ Interventions } \\
\hline \multicolumn{2}{|l|}{ Outcomes } \\
\hline \multicolumn{2}{|l|}{ Starting date } \\
\hline \multicolumn{2}{|r|}{ Nic Gwatkin, Head of Marketing, Novartis Ophthalmics } \\
\hline \multicolumn{2}{|l|}{ Notes } \\
\hline Study & VER \\
\hline Trial name or title & Visudyne in Early Retreatment Phase IIIB clinical trial \\
\hline \multirow[t]{2}{*}{ Participants } & People with predominantly classic CNV \\
\hline & 321 people at 31 sites enrolled \\
\hline Interventions & Visudyne therapy every 3 months (standard) versus more frequent regiment \\
\hline \multicolumn{2}{|l|}{ Outcomes } \\
\hline Starting date & Results expected at end 2003 \\
\hline Contact information & Nic Gwatkin, Head of Marketing, Novartis Ophthalmics \\
\hline Notes & \\
\hline
\end{tabular}




\section{Characteristics of ongoing studies (Continued)}

\begin{tabular}{ll} 
Study & VIM \\
\hline Trial name or title & Visudyne in Minimally Classic study \\
\hline Participants & \\
\hline Interventions & Visudyne therapy versus visudyne therapy with reduced light intensity versus placebo \\
\hline Outcomes & \\
\hline Starting date & Nic Gwatkin, Head of Marketing, Novartis Ophthalmics \\
\hline Contact information & VIO \\
\hline Notes & Visudyne therapy in Occult Phase III trial \\
\hline Study & People with occult but no classic CNV due to AMD \\
\hline Trial name or title & \\
\hline Participants & \\
\hline Interventions & Nic Gwatkin, Head of Marketing, Novartis Ophthalmics \\
\hline Outcomes & \\
\hline Starting date & \\
\hline Contact information & Notes \\
\hline
\end{tabular}

\section{A N A L Y S E S}

\section{Comparison 01. PHOTODYNAMIC THERAPY WITH VERTEPORFIN VERSUS PLACEBO}

\begin{tabular}{|c|c|c|c|c|}
\hline Outcome title & $\begin{array}{l}\text { No. of } \\
\text { studies }\end{array}$ & $\begin{array}{c}\text { No. of } \\
\text { participants }\end{array}$ & Statistical method & Effect size \\
\hline $\begin{array}{l}01 \text { Overall effect: }>=3 \text { lines lost at } \\
12 \text { months }\end{array}$ & 2 & 948 & Relative Risk (Fixed) 95\% CI & $0.80[0.70,0.91]$ \\
\hline $\begin{array}{l}02 \text { Overall effect: }>=3 \text { lines lost at } \\
24 \text { months }\end{array}$ & 2 & 948 & Relative Risk (Fixed) 95\% CI & $0.77[0.69,0.87]$ \\
\hline $\begin{array}{l}03 \text { Overall effect: }>=6 \text { lines lost at } \\
12 \text { months }\end{array}$ & & & Relative Risk (Fixed) 95\% CI & Totals not selected \\
\hline $\begin{array}{l}04 \text { Overall effect: }>=6 \text { lines lost at } \\
24 \text { months }\end{array}$ & 2 & 948 & Relative Risk (Fixed) 95\% CI & $0.62[0.50,0.76]$ \\
\hline $\begin{array}{l}05 \text { Classic CNV subgroups: >=3 } \\
\text { lines lost at } 12 \text { months }\end{array}$ & & & Relative Risk (Fixed) 95\% CI & Totals not selected \\
\hline $\begin{array}{l}06 \text { Classic CNV subgroups: >=3 } \\
\text { lines lost at } 24 \text { months }\end{array}$ & 6 & 942 & Relative Risk (Fixed) 95\% CI & $0.77[0.69,0.87]$ \\
\hline $\begin{array}{l}07 \text { Overall effect: contrast } \\
\text { sensitivity: >= } 6 \text { letters lost at } \\
24 \text { months }\end{array}$ & & & Relative Risk (Fixed) 95\% CI & Totals not selected \\
\hline $\begin{array}{l}08 \text { Overall effect: contrast } \\
\text { sensitivity: >= } 15 \text { letters lost at } \\
24 \text { months }\end{array}$ & & & Relative Risk (Fixed) 95\% CI & Totals not selected \\
\hline $\begin{array}{l}09 \text { Adverse effects: acute severe } \\
\text { visual acuity decrease }\end{array}$ & 2 & 948 & Risk Difference (Fixed) 95\% CI & $0.02[0.01,0.03]$ \\
\hline $\begin{array}{l}10 \text { Adverse effects: visual } \\
\text { disturbance }\end{array}$ & 2 & 948 & Relative Risk (Fixed) 95\% CI & $1.61[1.24,2.09]$ \\
\hline 11 Adverse effects: injection site & 2 & 948 & Odds Ratio (Fixed) 95\% CI & $2.54[1.50,4.31]$ \\
\hline
\end{tabular}




\begin{tabular}{lcccc}
$\begin{array}{l}12 \text { Adverse effects: infusion-related } \\
\text { back pain }\end{array}$ & 2 & 948 & Odds Ratio (Fixed) 95\% CI & $8.40[1.11,63.58]$ \\
$\begin{array}{l}13 \text { Adverse effects: allergic } \\
\text { reactions }\end{array}$ & 2 & 948 & Odds Ratio (Fixed) $95 \%$ CI & $0.94[0.34,2.56]$ \\
$\begin{array}{l}14 \text { Adverse effects: photosensitivity } \\
\text { reactions }\end{array}$ & 2 & 948 & Odds Ratio (Fixed) $95 \%$ CI & $5.37[1.01,28.60]$ \\
\hline
\end{tabular}

\section{NDEX TERMS}

\section{Medical Subject Headings (MeSH)}

Glucose [therapeutic use]; Macular Degeneration [*drug therapy]; *Photochemotherapy; Photosensitizing Agents [*therapeutic use]; Porphyrins [therapeutic use]; Randomized Controlled Trials; Retinal Neovascularization [ ${ }^{*}$ drug therapy]

MeSH check words

Humans

\section{COVER SHE T}

Title

Authors

Contribution of author(s)

Issue protocol first published

Review first published

Date of most recent amendment

Date of most recent

SUBSTANTIVE amendment

What's New

\section{Date new studies sought but none found}

Date new studies found but not yet included/excluded

Date new studies found and included/excluded

Date authors' conclusions section amended

Contact address
Photodynamic therapy for neovascular age-related macular degeneration

Wormald R, Evans J, Smeeth L, Henshaw K

RW participated in protocol development, study selection and assessment and writing up of the original and update of the review.

JE participated in protocol development, study selection and assessment, data abstraction and entry and writing up of the original and update of the review.

LS participated in protocol development, study selection and assessment, data abstraction and entry and writing up of the original and update of the review.

$\mathrm{KH}$ abstracted data and entered data into RevMan for the update of the review and participated in the updating of the review text.

l

$2000 / 2$

26 August 2005

23 August 2005

No new trials have been identified but new outcomes from existing trials have been reported on both effectiveness and adverse outcomes.

11 January 2005

Information not supplied by author

03 January 2003

23 August 2005

Mr Richard Wormald

Consultant Ophthalmologist and Honorary Senior Lecturer

Research and Development Department 


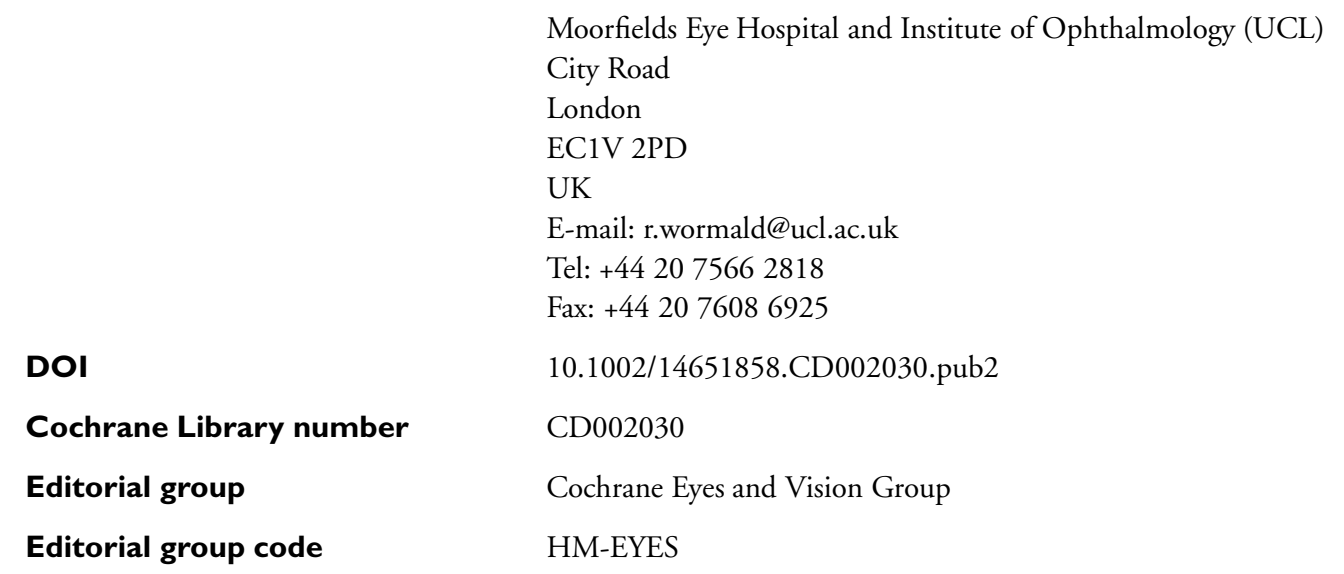

GRAPHS AND OTHER TABLES

Analysis 01.0I. Comparison 0I PHOTODYNAMIC THERAPY WITH VERTEPORFIN VERSUS PLACEBO, Outcome 01 Overall effect: >=3 lines lost at 12 months

Review: Photodynamic therapy for neovascular age-related macular degeneration

Comparison: OI PHOTODYNAMIC THERAPY WITH VERTEPORFIN VERSUS PLACEBO

Outcome: 0 I Overall effect: $>=3$ lines lost at 12 months

\begin{tabular}{|c|c|c|c|c|c|}
\hline Study & $\begin{array}{l}\text { PDT } \\
n / N\end{array}$ & $\begin{array}{l}\text { Placebo } \\
\mathrm{n} / \mathrm{N}\end{array}$ & $\begin{array}{c}\text { Relative Risk (Fixed) } \\
\qquad 95 \% \mathrm{Cl}\end{array}$ & $\begin{array}{l}\text { Weight } \\
(\%)\end{array}$ & $\begin{array}{c}\text { Relative Risk (Fixed) } \\
95 \% \mathrm{Cl}\end{array}$ \\
\hline TAP 1999 & $156 / 402$ & $111 / 207$ & 口a & 64.0 & $0.72[0.61,0.86]$ \\
\hline VIP 200I & $114 / 225$ & $62 / 114$ & 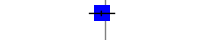 & 36.0 & $0.93[0.75,1.15]$ \\
\hline Total (95\% Cl) & 627 & 321 & - & 100.0 & $0.80[0.70,0.91]$ \\
\hline \multicolumn{6}{|c|}{ Total events: 270 (PDT), 173 (Placebo) } \\
\hline \multicolumn{6}{|c|}{ Test for heterogeneity chi-square $=3.23 \mathrm{df}=|\mathrm{p}=0.07|^{2}=69.0 \%$} \\
\hline Test for overall & $p=0.001$ & & & & \\
\hline
\end{tabular}


Analysis 01.02. Comparison 0I PHOTODYNAMIC THERAPY WITH VERTEPORFIN VERSUS PLACEBO, Outcome 02 Overall effect: >=3 lines lost at 24 months

Review: Photodynamic therapy for neovascular age-related macular degeneration

Comparison: OI PHOTODYNAMIC THERAPY WITH VERTEPORFIN VERSUS PLACEBO

Outcome: 02 Overall effect: $>=3$ lines lost at 24 months

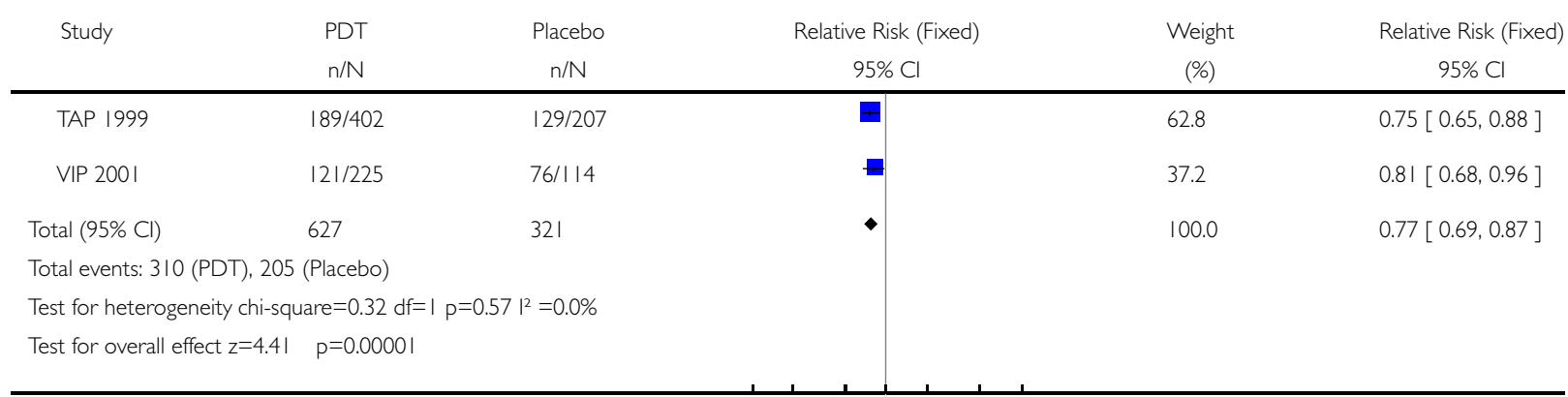

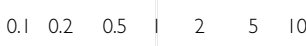

Favours PDT Favours placebo

Analysis 01.03. Comparison 0I PHOTODYNAMIC THERAPY WITH VERTEPORFIN VERSUS PLACEBO, Outcome 03 Overall effect: $>=6$ lines lost at 12 months

Review: Photodynamic therapy for neovascular age-related macular degeneration

Comparison: 0 I PHOTODYNAMIC THERAPY WITH VERTEPORFIN VERSUS PLACEBO

Outcome: 03 Overall effect: $>=6$ lines lost at 12 months

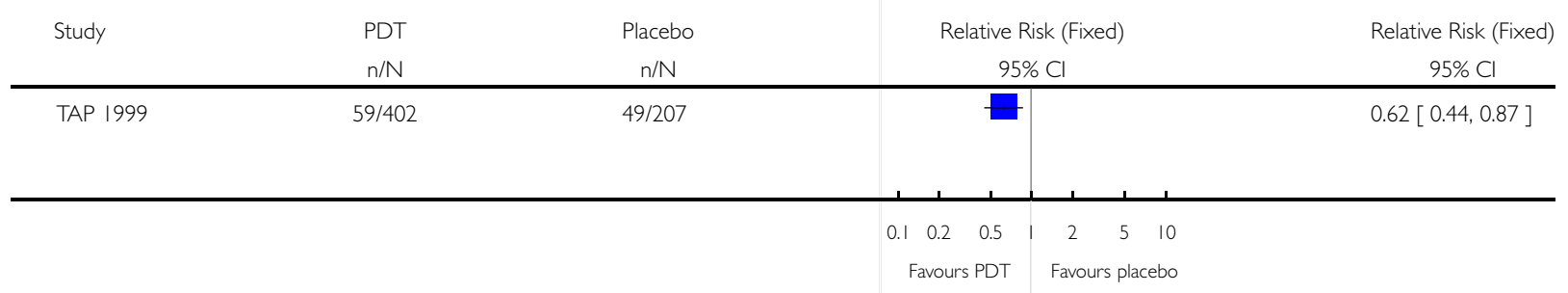


Analysis 01.04. Comparison 0I PHOTODYNAMIC THERAPY WITH VERTEPORFIN VERSUS PLACEBO, Outcome 04 Overall effect: >=6 lines lost at 24 months

Review: Photodynamic therapy for neovascular age-related macular degeneration

Comparison: 0 I PHOTODYNAMIC THERAPY WITH VERTEPORFIN VERSUS PLACEBO

Outcome: 04 Overall effect: $>=6$ lines lost at 24 months

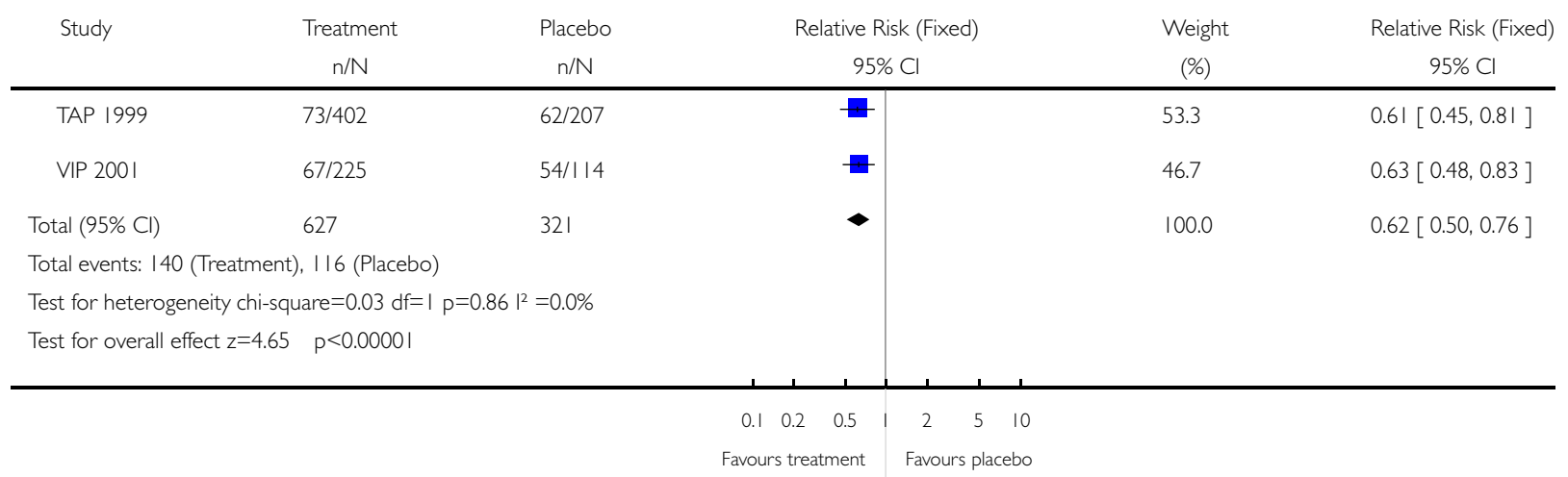

Analysis 01.05. Comparison OI PHOTODYNAMIC THERAPY WITH VERTEPORFIN VERSUS PLACEBO, Outcome 05 Classic CNV subgroups: >=3 lines lost at 12 months

Review: Photodynamic therapy for neovascular age-related macular degeneration

Comparison: 0 I PHOTODYNAMIC THERAPY WITH VERTEPORFIN VERSUS PLACEBO

Outcome: 05 Classic CNV subgroups: >=3 lines lost at 12 months

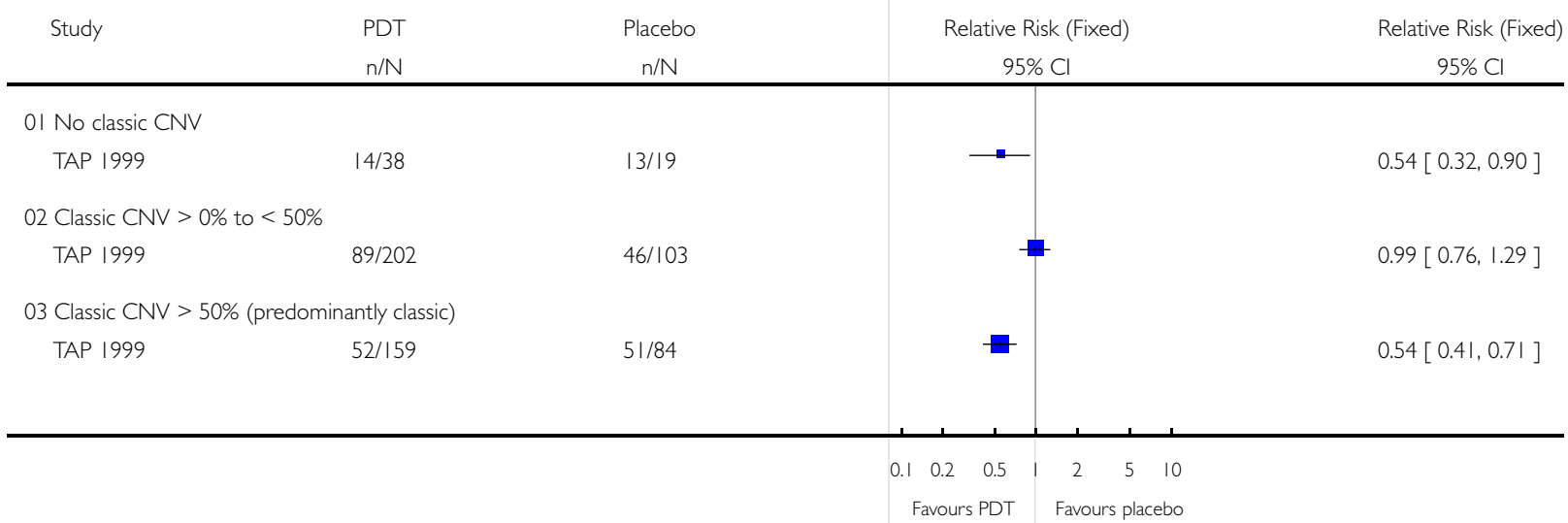




\section{Analysis 01.06. Comparison 0I PHOTODYNAMIC THERAPY WITH VERTEPORFIN VERSUS PLACEBO,}

Outcome 06 Classic CNV subgroups: >=3 lines lost at 24 months

\begin{tabular}{|c|c|c|c|c|c|}
\hline \multicolumn{6}{|c|}{$\begin{array}{l}\text { Comparison: } 0 \text { I PHOTODYNAMIC THERAPY WITH VERTEPORFIN VERSUS PLACEBO } \\
\text { Outcome: } 06 \text { Classic CNV subgroups: >=3 lines lost at } 24 \text { months }\end{array}$} \\
\hline \multirow[t]{2}{*}{ Study } & PDT & Placebo & Relative Risk (Fixed) & Weight & Relative Risk (Fixed) \\
\hline & $\mathrm{n} / \mathrm{N}$ & $\mathrm{n} / \mathrm{N}$ & $95 \% \mathrm{Cl}$ & $(\%)$ & $95 \% \mathrm{Cl}$ \\
\hline \multicolumn{6}{|l|}{ OI No classic CNV } \\
\hline TAP 1999 & $|8 / 4|$ & $14 / 20$ & $\longrightarrow$ & 7.0 & $0.63[0.40,0.98]$ \\
\hline VIP 2001 & $91 / 166$ & $63 / 92$ & - & 30.0 & $0.80[0.66,0.97]$ \\
\hline Subtotal $(95 \% \mathrm{Cl})$ & 207 & 112 & $\bullet$ & 37.0 & $0.77[0.64,0.92]$ \\
\hline \multicolumn{6}{|c|}{ Total events: 109 (PDT), 77 (Placebo) } \\
\hline \multicolumn{6}{|c|}{ Test for heterogeneity chi-square $=0.95 \mathrm{df}=\mid \mathrm{p}=0.33 \mathrm{|}^{2}=0.0 \%$} \\
\hline \multicolumn{6}{|c|}{ Test for overall effect $z=2.89 \quad p=0.004$} \\
\hline \multicolumn{6}{|c|}{02 Classic CNV $>0$ to $<50 \%$} \\
\hline TAP 1999 & 106/202 & $58 / 104$ & - & 28.4 & $0.94[0.76,1.17]$ \\
\hline VIP 2001 & 19/38 & $10 / 18$ & $\longrightarrow$ & 5.0 & $0.90[0.53,1.52]$ \\
\hline Subtotal $(95 \% \mathrm{Cl})$ & 240 & 122 & $\bullet$ & 33.4 & $0.93[0.77,1.14]$ \\
\hline \multicolumn{6}{|c|}{ Total events: 125 (PDT), 68 (Placebo) } \\
\hline \multicolumn{6}{|c|}{ Test for heterogeneity chi-square $=0.02 \mathrm{df}=\mid \mathrm{p}=0.88 \mathrm{I}^{2}=0.0 \%$} \\
\hline \multicolumn{6}{|c|}{ Test for overall effect $z=0.66 \quad p=0.5$} \\
\hline \multicolumn{6}{|c|}{03 Classic CNV > 50\% (predominantly classic) } \\
\hline TAP 1999 & $65 / 159$ & $57 / 83$ & 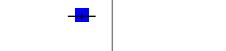 & 27.7 & $0.60[0.47,0.75]$ \\
\hline VIP 200I & $10 / 16$ & $3 / 3$ & $一$ & 1.9 & $0.63[0.43,0.91]$ \\
\hline Subtotal $(95 \% \mathrm{Cl})$ & 175 & 86 & $\bullet$ & 29.6 & $0.60[0.48,0.75]$ \\
\hline \multicolumn{6}{|c|}{ Total events: 75 (PDT), 60 (Placebo) } \\
\hline \multicolumn{6}{|c|}{ Test for heterogeneity chi-square $=0.06 \mathrm{df}=|\mathrm{p}=0.8| \mathrm{I}^{2}=0.0 \%$} \\
\hline \multicolumn{6}{|c|}{ Test for overall effect $z=4.54 \quad p<0.0000$ I } \\
\hline Total $(95 \% \mathrm{Cl})$ & 622 & 320 & - & 100.0 & $0.77[0.69,0.87]$ \\
\hline \multicolumn{6}{|c|}{ Total events: 309 (PDT), 205 (Placebo) } \\
\hline \multicolumn{6}{|c|}{ Test for heterogeneity chi-square $=10.36 \mathrm{df}=5 \mathrm{p}=0.07 \mathrm{I}^{2}=51.7 \%$} \\
\hline Test for overall effe & $p=0.00001$ & & & & \\
\hline
\end{tabular}


Analysis 01.07. Comparison 0I PHOTODYNAMIC THERAPY WITH VERTEPORFIN VERSUS PLACEBO, Outcome 07 Overall effect: contrast sensitivity: >= 6 letters lost at 24 months

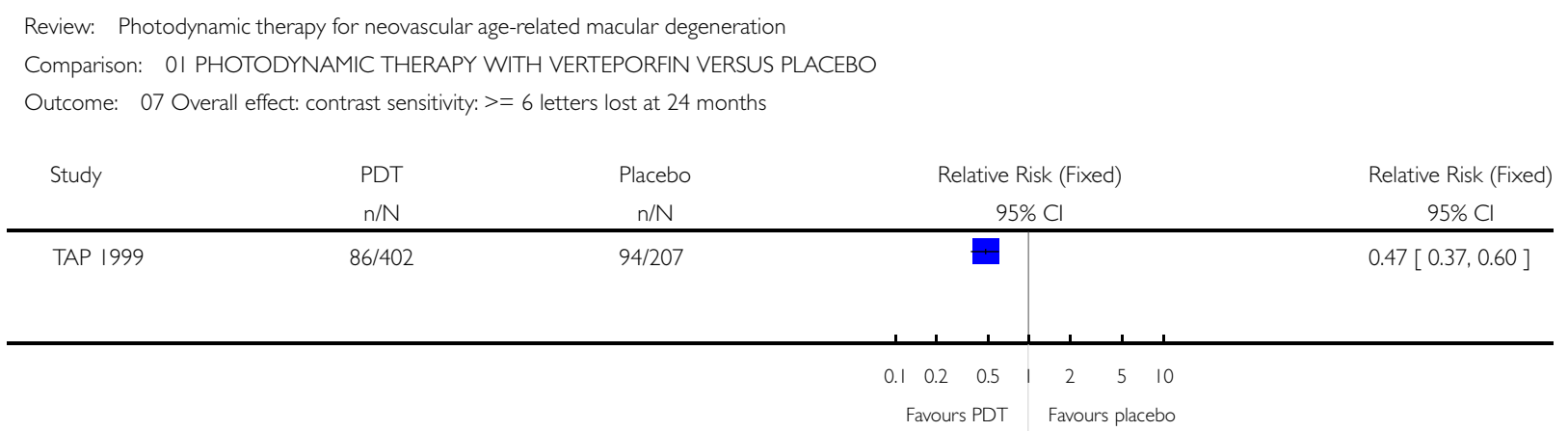

Analysis 01.08. Comparison 0I PHOTODYNAMIC THERAPY WITH VERTEPORFIN VERSUS PLACEBO, Outcome 08 Overall effect: contrast sensitivity: >= 15 letters lost at 24 months

Review: Photodynamic therapy for neovascular age-related macular degeneration

Comparison: 0 I PHOTODYNAMIC THERAPY WITH VERTEPORFIN VERSUS PLACEBO

Outcome: 08 Overall effect: contrast sensitivity: >= 15 letters lost at 24 months

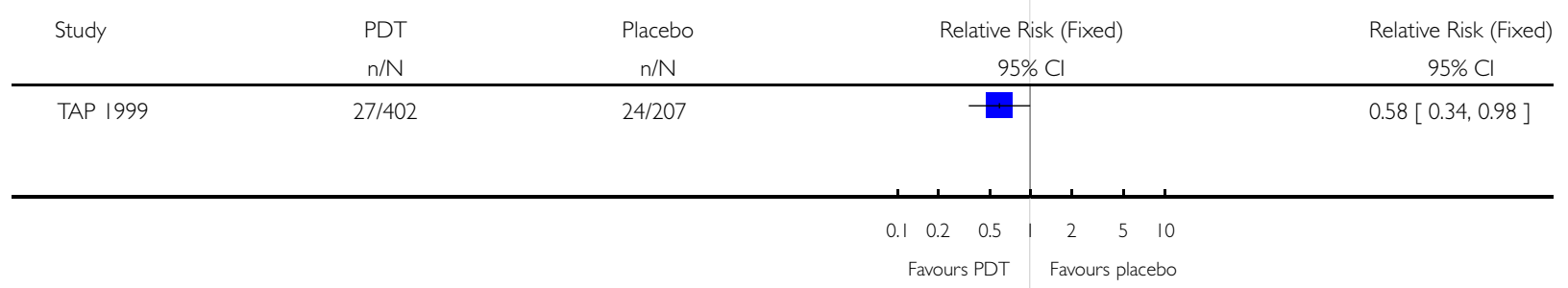

Analysis 01.09. Comparison 0I PHOTODYNAMIC THERAPY WITH VERTEPORFIN VERSUS PLACEBO, Outcome 09 Adverse effects: acute severe visual acuity decrease

Review: Photodynamic therapy for neovascular age-related macular degeneration

Comparison: OI PHOTODYNAMIC THERAPY WITH VERTEPORFIN VERSUS PLACEBO

Outcome: 09 Adverse effects: acute severe visual acuity decrease

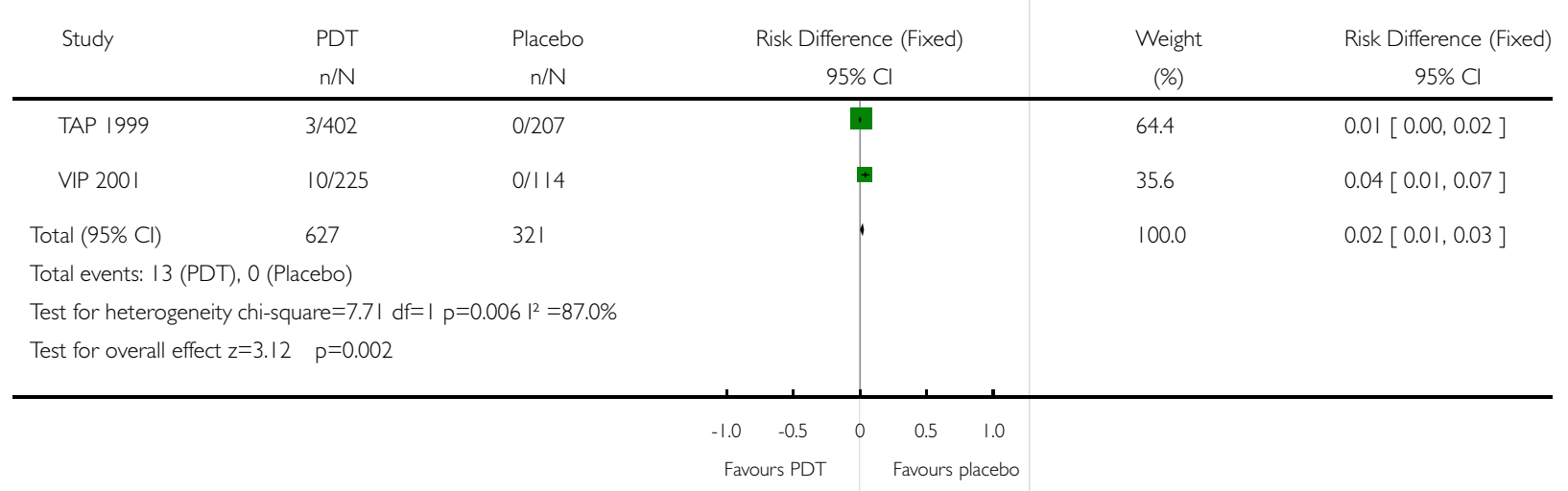

Photodynamic therapy for neovascular age-related macular degeneration (Review) 


\section{Analysis 0I.I0. Comparison 0I PHOTODYNAMIC THERAPY WITH VERTEPORFIN VERSUS PLACEBO,}

Outcome 10 Adverse effects: visual disturbance

Review: Photodynamic therapy for neovascular age-related macular degeneration

Comparison: OI PHOTODYNAMIC THERAPY WITH VERTEPORFIN VERSUS PLACEBO

Outcome: 10 Adverse effects: visual disturbance

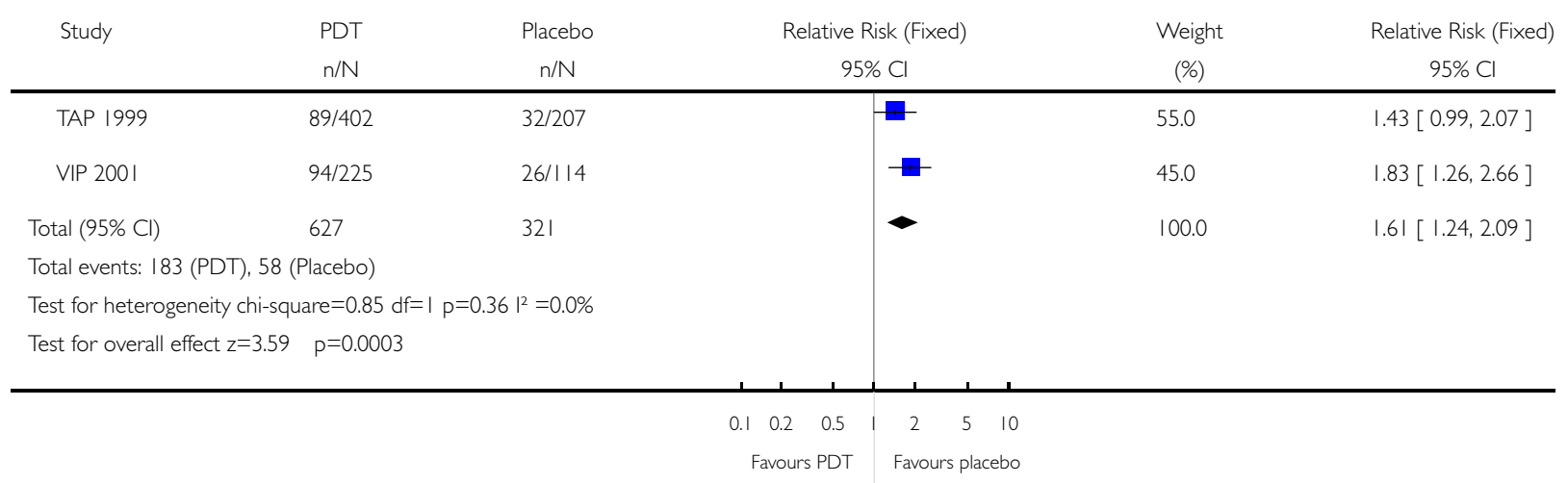

Analysis 0I.II. Comparison 0I PHOTODYNAMIC THERAPY WITH VERTEPORFIN VERSUS PLACEBO, Outcome II Adverse effects: injection site

Review: Photodynamic therapy for neovascular age-related macular degeneration

Comparison: OI PHOTODYNAMIC THERAPY WITH VERTEPORFIN VERSUS PLACEBO

Outcome: II Adverse effects: injection site

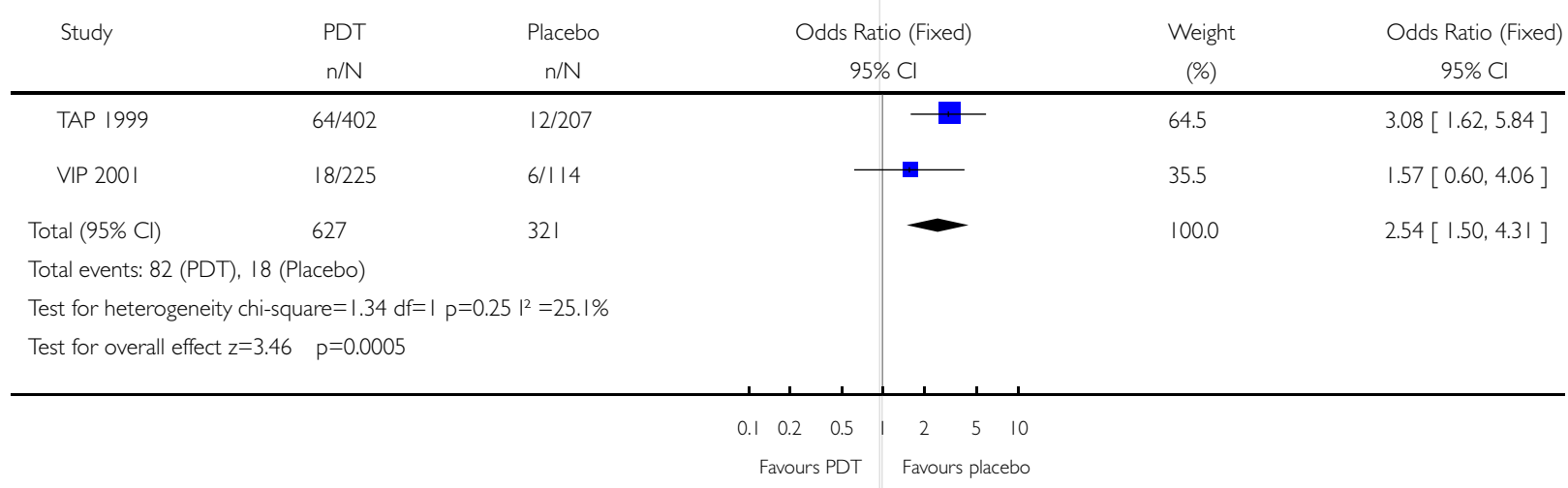


Analysis 0I.I2. Comparison 0I PHOTODYNAMIC THERAPY WITH VERTEPORFIN VERSUS PLACEBO, Outcome 12 Adverse effects: infusion-related back pain

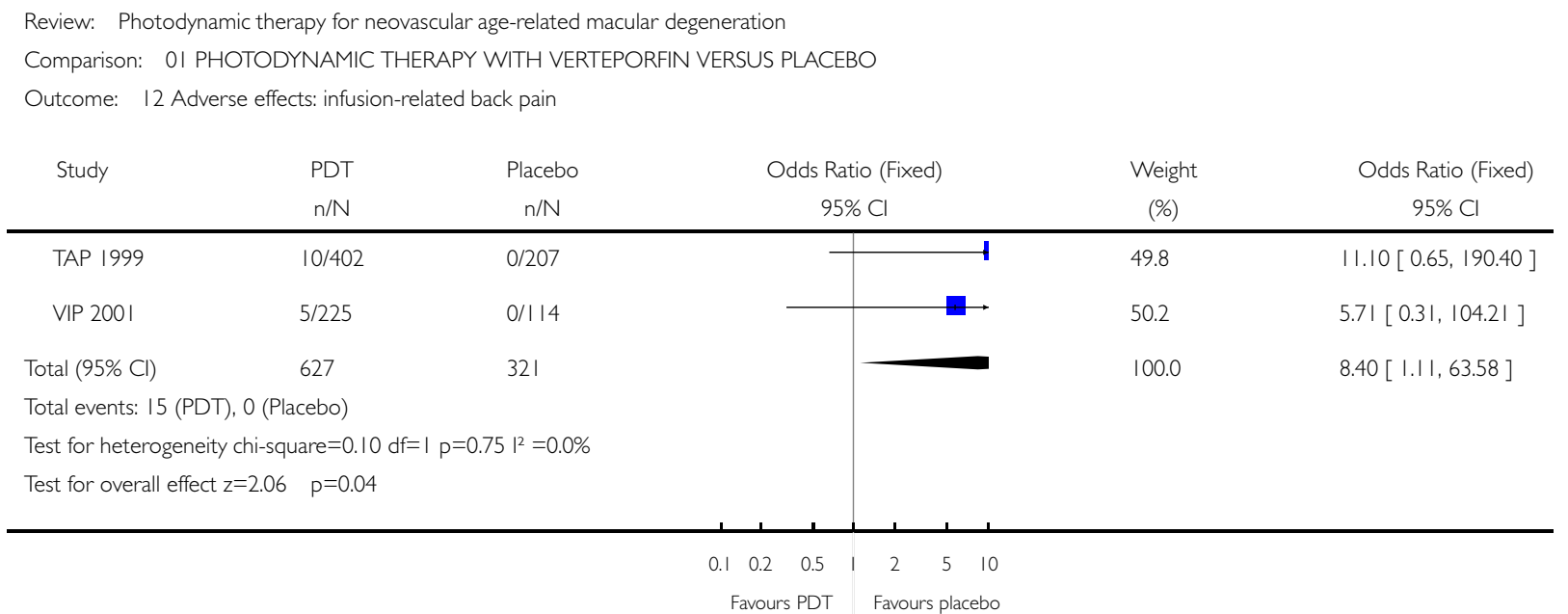

Analysis 0I.13. Comparison 0I PHOTODYNAMIC THERAPY WITH VERTEPORFIN VERSUS PLACEBO, Outcome 13 Adverse effects: allergic reactions

Review: Photodynamic therapy for neovascular age-related macular degeneration

Comparison: OI PHOTODYNAMIC THERAPY WITH VERTEPORFIN VERSUS PLACEBO

Outcome: 13 Adverse effects: allergic reactions

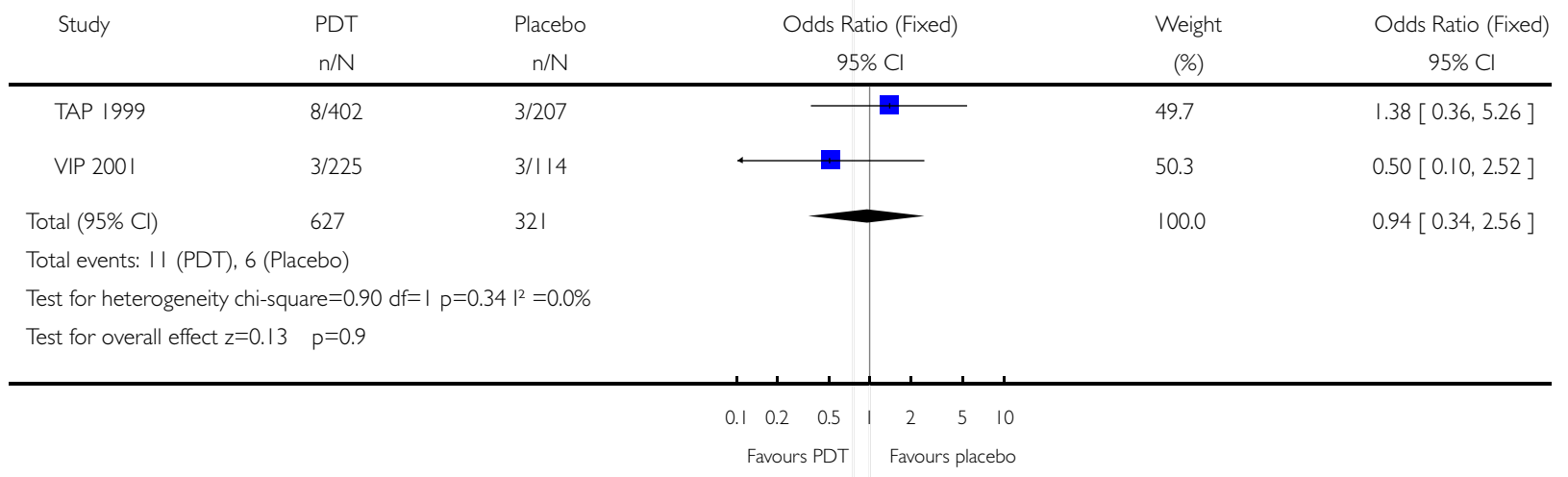


Analysis 0I.I4. Comparison OI PHOTODYNAMIC THERAPY WITH VERTEPORFIN VERSUS PLACEBO, Outcome 14 Adverse effects: photosensitivity reactions

Review: Photodynamic therapy for neovascular age-related macular degeneration

Comparison: OI PHOTODYNAMIC THERAPY WITH VERTEPORFIN VERSUS PLACEBO

Outcome: 14 Adverse effects: photosensitivity reactions

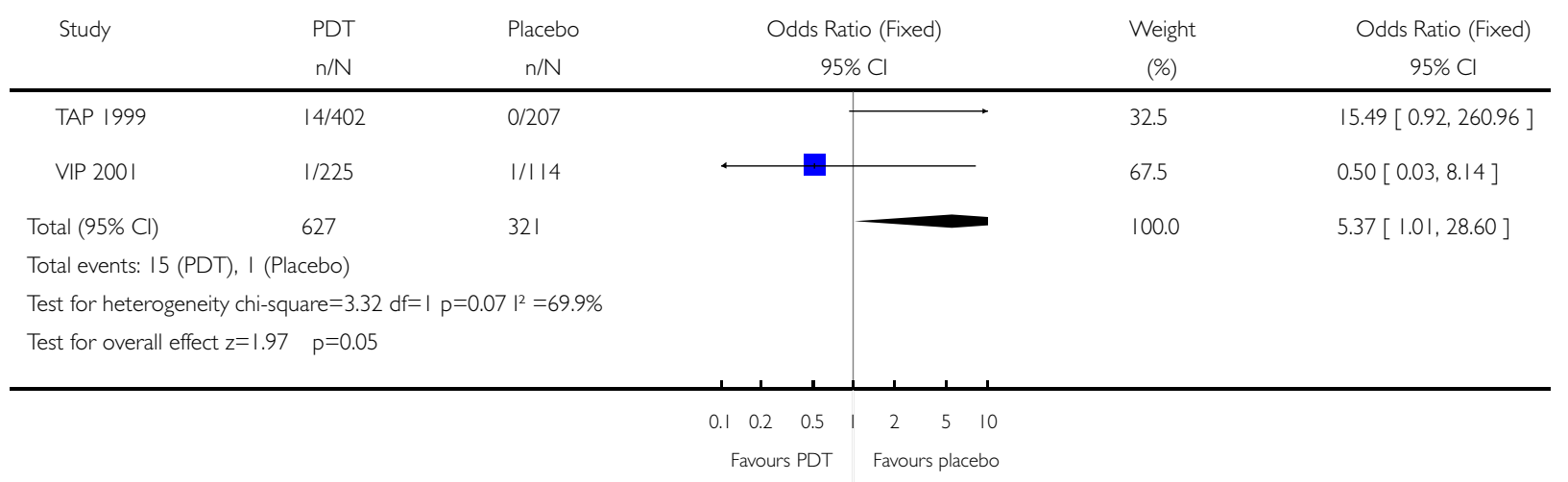

